\title{
Avaliação de dispositivos de sombreamento no RTQ-R do ponto de vista térmico e luminoso
}

RTQ-R's shadings devices evaluation from a thermal and luminous point of view

\section{Roberta Vieira Gonçalves de Souza \\ Carla Patrícia Santos Soares Tatiana Paula Alves}

\section{${ }^{1}$ Roberta Vieira Gonçalves de \\ Souza \\ Departamento de Tecnologia da Arquitetura e do Urbanismo, Escola de Arquitetura \\ ${ }^{1}$ Universidade Federal de Minas \\ Rua Paraíba, 697, Sala 124, Funcionários \\ Belo Horizonte - MG - Brasil CEP 30130-140 \\ Tel.: (31) 3409-8872 \\ E-mail: roberta@arq.ufmg.br}

\section{${ }^{2}$ Carla Patrícia Santod Soares \\ ${ }^{2}$ Ares Arquitetura Ltda ME Rua Rio Grande do Norte, 1560, Sala 604, Funcionários \\ Belo Horizonte - MG - Brasi CEP 30130-131 \\ Tel.: (31) 2516-8777 \\ E-mail: pati.incd@gmail.com \\ ${ }^{3}$ Tatiana Paula Alves \\ ${ }^{3}$ Centro Universitário UNA \\ Rua Aimorés, 1451, Lourdes Belo \\ Horizonte - MG - Brasil CEP 30140-071 \\ Tel.: (31) 2516-8777 \\ E-mail: alvestatianapaula@gmail.com}

Recebido em 30/12/17

Aceito em 08/04/18

\section{Resumo}

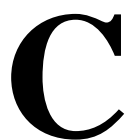

onsidera-se que o Regulamento Brasileiro de Eficiência Energética em Edificações Residenciais (RTQ-R, 2012) apresenta um sistema de pontuação que desvaloriza o uso de dispositivos de sombreamento para as aberturas que não venezianas. Esses dispositivos são considerados com peso máximo de 50\% em relação à pontuação das venezianas ainda que apresentem desempenho superior a esse peso. O presente estudo investigou o desempenho térmico e luminoso de diferentes tipologias de proteção solar em aberturas a fim de propor uma adequação do sistema de pontuações desses dispositivos pelo RTQ-R. Para tanto, foram feitas simulações computacionais com aberturas para quatro orientações em sete zonas bioclimáticas brasileiras e com variações nas tipologias e do acionamento dos dispositivos de proteção solar para ambientes de dormitório e de estar. A partir das simulações computacionais realizadas foi proposta uma escala única de pontuação para os dispositivos de sombreamento. Os resultados das pontuações indicam valores significativamente superiores ao máximo atribuído às venezianas pelo RTQ-R, o que mostra uma distorção entre os valores resultantes das simulações e os valores praticados pelo RTQ-R. Observou-se que as pontuações variam significativamente tanto entre as zonas bioclimáticas quanto com a orientação solar, e, por isso, o estudo propõe um critério de pontuação que considere essas variáveis.

Palavras-chave: Proteção solar. Eficiência energética. RTQ-R.

\section{Abstract}

Currently, the Brazilian Energy Labelling System for Residential Buildings, RTQ$R$ (BRASIL, 2012) values non-venetian shading devices with a maximum weight of $50 \%$ of the venetians performance, even though those shading devices show more effective thermal and daylighting performance. This study investigated the energy savings potential as well as the thermal and luminous performance of different shading devices in order to propose an adequacy of the current RTQ-R shading device rating system. Moreover, computational simulations were performed for four orientations in seven Brazilian bioclimatic zones and with seven different shading devices. From the computational simulations performed, a single rating system was proposed. The results indicated a considerable distortion between the simulations and the RTQ-R scores. Bioclimatic zones and solar orientation were noted to have a significant impact on the simulation scores, and, therefore, the study proposes a method that integrates both topics in the shading device rating system.

Keywords: Solar shading devices. Energy efficiency. RTQ-R. 


\section{Introdução}

Como resposta à tendência crescente do uso de energia em edifícios, governos e autoridades em todo o mundo, vem adotando políticas e medidas que visam reduzir o consumo de energia e promover a eficiência energética em edifícios (IWARO; MWASHA, 2010). No Brasil, os primeiros passos em direção à eficiência energética de edifícios foram dados em 2001 com a promulgação da Lei 10.295 - Lei de Eficiência Energética, que estabeleceu os princípios básicos para a política nacional de conservação de energia. Nesse contexto foram desenvolvidos o Regulamento Técnico da Qualidade para o Nível de Eficiência Energética de Edifícios Comerciais, de Serviços e Públicos (RTQC) e o Regulamento de Edificações Residenciais (RTQ-R). De modo geral, esses regulamentos visam estipular referências quanto ao desempenho energético das edificações avaliando estratégias de projeto quanto às propriedades termofísicas das envoltórias, ventilação e iluminação natural, sistemas de sombreamento, desempenho de aquecimento de água e equipamentos.

Destaca-se nesse contexto o papel fundamental dos sistemas de esquadrias no desempenho térmico e luminoso das edificações, sendo esses responsáveis por regular o ganho de calor e luz dos ambientes internos (FONTENELLE; BASTOS, 2014). Admitir luz natural pelas aberturas de forma a garantir adequados níveis de iluminação e de distribuição no ambiente, controlando os respectivos ganhos de calor solar e mediante um equilíbrio termoluminoso, é considerada uma árdua tarefa por arquitetos e projetistas (BOGO; PEREIRA; CLARO, 2009).

No contexto brasileiro atual, pesquisas como as desenvolvidas por Santana e Ghisi (2009), Didoné (2009), Silva (2011) e Cintra (2011) buscam maneiras para melhor compreender e aplicar a luz natural nas edificações. Santana e Ghisi (2009) e Didoné (2009) reforçaram a necessidade de um projeto adequado de proteção solar que considere o estudo da trajetória solar, bem como as características climáticas locais para a redução do consumo de energia em edificações. Silva (2011) e Cintra (2011) salientaram a importância de integrar a luz natural a sistemas de iluminação artificial e dispositivos de proteção solar de forma a garantir maior desempenho térmico ao ambiente e, assim, promover a eficiência energética em edificações. De modo geral, esses trabalhos apontam as proteções solares como elementos fundamentais na melhoria do desempenho térmico das edificações em climas quentes.

Em se tratando de sistemas de proteção solar, destacam-se alguns trabalhos com abordagens capazes de considerar os critérios térmicos e luminosos simultaneamente, como Lima, Bittencourt e Caram (2013) e Manzan (2014), que estudam a relação da geometria dos dispositivos de controle solar no desempenho do ambiente interno, e Lee et al. (2016) e Carletti et al. (2016), que avaliam a performance termoluminosa de sistemas de proteção solar automatizados. De modo geral, esses trabalhos evidenciam a complexidade de conciliar os aspectos térmicos e luminosos no desenvolvimento de sistemas de proteção solar.

Atualmente, no RTQ-R a avaliação da contribuição térmica dos dispositivos de proteção solar externos às aberturas é definida pela variável Somb, que varia de 0 a 1 , sendo Somb $=0$ quando não houver dispositivos de proteção solar e Somb $=1$ quando houver venezianas que cubram $100 \%$ da abertura quando fechadas. Dispositivos que não as venezianas são pontuados por meio de dois métodos, podendo receber pontuações de até 0,5 ou de até 0,2 em função do método utilizado. O Somb faz parte das equações prescritivas definidas para cada conjunto de zonas bioclimáticas, e seu peso é variável em cada zona. No entanto, verifica-se que a presença do Somb pode levar ambientes a melhorar sua classificação em até um nível, apesar de o peso relativo dessa variável nas equações prescritivas do RTQ-R ter sido considerado pequeno por Telles e Carlo (2016) em uma análise de sensibilidade global com coeficiente de correlação parcial (CCP) inferior a |0,700|.

O primeiro método de análise do Somb, descrito no Anexo I do RTQ-R (INSTITUTO..., 2012), permite a definição de valores entre 0 e 0,5 para a variável e define os ângulos para a determinação de dimensões mínimas do sistema de proteção solar utilizando como referência a metodologia proposta por Pereira e Souza (2008). O RTQ-R disponibiliza tabelas de ângulos mínimos de proteção de acordo com a orientação e porcentagem de área de janela para 213 cidades brasileiras.

Nesse método a variável Somb $b_{a b e r t u r a}$ é calculada utilizando-se a seguinte Equação 1:

$s o m b_{\text {abertura }}=\frac{(\alpha \mathrm{p}+\gamma \mathrm{ep}+\gamma \mathrm{dp}+\beta \mathrm{ep}+\beta \mathrm{dp})}{(\alpha \mathrm{r}+\gamma \mathrm{er}+\gamma \mathrm{dr}+\beta \mathrm{er}+\beta \mathrm{dr})}$ Eq. 1

Onde as letras p e r referem-se a ângulos de projeto (p) e a ângulos recomendados (r), e as outras letras referem-se aos ângulos das proteções da seguinte forma:

$\alpha$ : ângulo de proteção horizontal;

$\gamma_{\mathrm{e}}$ : ângulo de extensão lateral esquerdo;

$\gamma_{\mathrm{d}}$ : ângulo de extensão lateral direito; 
$\beta_{\mathrm{e}}$ : ângulo de proteção vertical esquerdo; e

$\beta_{\mathrm{d}}$ : ângulo de proteção vertical direito.

O valor de Somb $b_{a b e r t u r a}$ resulta em um valor percentual que é utilizado para calcular-se Somb, considerando que 0,75 de Sombabertura corresponde a um valor de Somb igual a 0,5.

O segundo método define que pode ser adotado valor de Somb $=0,2$ para ambientes com sombreamento por varanda, beiral ou brise horizontal, desde que os ângulos de sombreamento alpha $(\alpha)$ e gama $(\gamma)$ atendam aos limites de ângulo mínimos para norte, sul, leste e oeste estabelecidos pelas seguintes equações, de acordo com a Nota Técnica 6 (PBE EDIFICA, 2012):

(a) limite para $\alpha$ ou $\gamma$ norte $=23,5^{\circ}$ - Lat;

(b) limite para $\alpha$ ou $\gamma$ sul $=23,5^{\circ}$ - Lat; e

(c) limite para $\alpha$ ou $\gamma$ leste e oeste $=45^{\circ}$.

onde Lat assume valores negativos para o hemisfério Sul; $\alpha$, ângulo de altitude solar a normal da fachada que limita a proteção solar; e $\gamma$, ângulo da altura solar perpendicular à normal da fachada que limita as laterais da proteção solar.

Em síntese, observa-se que o RTQ-R não permite aos brises ou demais sistemas de proteção alcançar a nota máxima (Somb = 1), ainda que os dispositivos em análise apresentem efetivo sombreamento no período de insolação. Distorções nessa escala de pontuação já haviam sido identificadas nos estudos realizados pelo Laboratório de Eficiência Energética em Edificações (LabEEE) da Universidade Federal de Santa Catarina (UFSC) (LABORATÓRIO..., 2011a) e por Santos (2009), que comprovaram que em algumas situações os ângulos mínimos avaliados pelos métodos contribuem apenas para obstruir parte da radiação solar e que não poderiam ser igualmente valorizados quando comparados a um sistema que obstrui a radiação solar durante um maior período num processo de avaliação de eficiência energética.

Considera-se que a correta pontuação do Somb seja importante especialmente para salas onde não há necessidade do escurecimento noturno fornecido pelas venezianas.

É importante também observar a não uniformidade da pontuação no cálculo da variável Somb, uma vez que um mesmo elemento de proteção poderia ser interpretado pelos métodos do regulamento recebendo pontuações variadas (veneziana, 0 ou 1; método do Anexo 1, de 0 a 0,5, e método da latitude, de 0 a 0,2). Sendo assim, entende-se que é necessário investigar como cada método avalia o desempenho do sombreamento da abertura.

Nesse contexto, o presente trabalho tem como objetivo contribuir para o aprimoramento do método de avaliação do sombreamento em aberturas pelo RTQ-R ao propor uma adequação das pontuações dos dispositivos de proteção solar, visando a uma maior valorização destes. A abordagem metodológica utiliza a simulação computacional de métricas dinâmicas para investigar a influência de dispositivos de proteção solar no comportamento térmico e luminoso de ambientes residenciais.

\section{Método}

A construção dos modelos para simulação do desempenho termoluminoso de ambientes residenciais foi baseada no Relatório Técnico da Base de Simulações para o RTQ-R (LABORATÓRIO..., 2011b). Foram desenvolvidas proteções solares para quatro orientações (norte, sul, leste e oeste) e avaliadas quanto a sua eficiência para sete cidades distribuídas nas diferentes zonas bioclimáticas brasileiras.

A eficiência dos dispositivos de sombreamento foi avaliada pela obtenção de graus-hora de aquecimento e de resfriamento calculados a partir da temperatura operativa. A Figura 1 apresenta uma síntese das etapas da metodologia desenvolvida no presente trabalho e seus produtos.

No presente estudo adotaram-se as cidades simuladas pelo LabEEE (LABORATÓRIO..., 2011a) na elaboração das equações do RTQ-R, conforme a Tabela 1.

Foram criados modelos de proteção solar e venezianas descritos em detalhe na Tabela 3. Os horários de análise da iluminação natural foram estipulados conforme proposto por Guedes (2012).

Com a definição dos modelos, construídos com o auxílio do Suntool, as simulações foram feitas em dois softwares: Daysim e EnergyPlus. O programa Daysim foi utilizado para gerar resultados referentes ao acionamento das venezianas e do sistema de iluminação artificial. Esses valores foram os dados de entrada no EnergyPlus, utilizado para gerar resultados referentes aos graus-hora de aquecimento e resfriamento. 
Figura 1 - Síntese das etapas metodológicas do presente trabalho

\begin{tabular}{|c|c|c|c|c|}
\hline $\begin{array}{l}\text { Construção dos } \\
\text { modelos }\end{array}$ & $\begin{array}{c}\text { Dimensionamento } \\
\text { dos dispositivos de } \\
\text { proteção solar }\end{array}$ & $\begin{array}{l}\text { Simulação de } \\
\text { Iluminação }\end{array}$ & $\begin{array}{c}\text { Simulação } \\
\text { termoenergética }\end{array}$ & $\begin{array}{l}\text { Tratamento de } \\
\text { dados }\end{array}$ \\
\hline $\begin{array}{l}\text { Investigação dos } \\
\text { modelos utilizados } \\
\text { para elaboração das } \\
\text { equações do RTQ-R }\end{array}$ & $\begin{array}{c}\text { Dimensionamento } \\
\text { dos dispositivos de } \\
\text { proteção solar a } \\
\text { partir dos métodos } \\
\text { de avaliação de } \\
\text { sombreamento pelo } \\
\text { RTQ-R }\end{array}$ & $\begin{array}{c}\text { Determinação do } \\
\text { acionamento das } \\
\text { venezianas de } \\
\text { proteção a partir da } \\
\text { insolação no plano }\end{array}$ & $\begin{array}{l}\text { Resultado do } \\
\text { número de graus- } \\
\text { hora de } \\
\text { aquecimento e de } \\
\text { resfriamento } \\
\text { calculados a partir }\end{array}$ & $\begin{array}{l}\text { Comparativo do } \\
\text { desempenho } \\
\text { térmico dos } \\
\text { modelos } \\
\text { condicionados } \\
\text { naturalmente }\end{array}$ \\
\hline $\begin{array}{c}\text { Definição de } \\
\text { variáveis } \\
\text { determinantes para } \\
\text { investigação do } \\
\text { desempenho de } \\
\text { dispositivos de } \\
\text { proteção solar }\end{array}$ & $\begin{array}{c}\text { Dimensionamento } \\
\text { de duas tipologias } \\
\text { de proteção a partir } \\
\text { do sombreamento } \\
\text { da abertura }\end{array}$ & excesso de brilho & $\begin{array}{c}\text { temperatura } \\
\text { operativa }\end{array}$ & $\begin{array}{c}\text { Discussão } \\
\text { comparativa entre o } \\
\text { resultado das } \\
\text { simulações e o } \\
\text { método de avaliação } \\
\text { de sombreamento } \\
\text { pelo RTQ-R }\end{array}$ \\
\hline
\end{tabular}

Tabela 1 - Indicação dos arquivos climáticos utilizados nas simulações

\begin{tabular}{c|l}
\hline Zona Bioclimática & \multicolumn{1}{|c}{$\begin{array}{c}\text { Arquivos do desenvolvimento das equações do } \\
\text { RTQ-R e adotados nas simulações deste trabalho }\end{array}$} \\
\hline ZB-1 & Curitiba - PR (TRY 1969) \\
ZB-2 & Santa Maria - RS (TMY2, SWERA) \\
ZB-3 & Florianópolis - SC (TRY 1963) \\
ZB-4 & Brasília - DF (TRY 1962) \\
ZB-6 & Campo Grande - MS (TMY2, SWERA) \\
ZB-7 & Cuiabá - MT (TMY2, SWERA) \\
ZB-8 & Salvador - BA (TRY 1961) \\
\hline
\end{tabular}

Fonte: LabEEE (LABORATÓRIO..., 2011a).

As análises de desempenho da iluminação natural foram construídas a partir de porcentagem de acionamento da iluminação artificial, e as análises térmicas foram geradas a partir de comparações do desempenho dos diferentes dispositivos. Por fim, as discussões acerca do método de avaliação da presença de sombreamento pelo RTQ-R possibilitaram a proposição de uma escala única para pontuação dos dispositivos de sombreamento no RTQ-R.

\section{Modelos adotados}

Para o desenvolvimento das análises foi adotado o modelo-base utilizado pelo RTQ-R na elaboração das equações preditivas. Esse modelo corresponde a um edifício residencial multifamiliar, e foram investigados os ambientes de dormitório e de estar. Os ambientes de estar foram avaliados como condicionados naturalmente, e os ambientes de dormitório, como condicionados natural e artificialmente.

Como o objeto do estudo foi a análise de sombreamento, não se variaram as características da envoltória em relação ao modelo-base utilizado pelo RTQ-R. Ressalta-se, no entanto, que em face de diferentes tipos de parede e cobertura, os resultados de graus-hora encontrados podem ser distintos daqueles aqui apresentados.

Os ambientes de estar e dormitório foram avaliados em um pavimento intermediário da edificação multifamiliar, conforme indicado na Figura 2.

\section{Parâmetros adotados para simulação}

As propriedades térmicas da envoltória foram fixadas e baseadas nas tipologias intermediárias adotadas por LabEEE (LABORATÓRIO..., 2011b). Os valores relativos a densidade, espessura e condutividade térmica são apresentados na Figura 3. 
A Tabela 2 apresenta as características da envoltória e das rotinas de uso adotadas nesta pesquisa.

Uma vez que esta pesquisa se propõe a avaliar as condições de desempenho de elementos de proteção solar projetados para barrar a insolação direta durante o período diurno, o padrão de ocupação foi determinado considerando-se que o quarto será ocupado por uma pessoa estudando ou trabalhando no período diurno. Apenas durante o horário de almoço ou ao anoitecer não foi prevista ocupação. A Figura 4 mostra as horas de ocupação consideradas.

\section{Dimensionamento dos dispositivos de proteção solar}

Para esta pesquisa foi estudado um total de sete tipologias de dispositivos comparadas a um modelo sem sombreamento (SP). Foram utilizados dispositivos de proteção externos às aberturas, compostos de duas maneiras:

(a) venezianas móveis acionadas pela época do ano (verão e inverno) de acordo com a zona bioclimática (VRTQ-R) e venezianas acionadas de acordo com o comportamento do usuário previsto no algoritmo Lightswitch do programa Daysim (V90 e V45); e

(b) elementos fixos de proteção solar (L23, TN, PTI e PTF).

Figura 2 - Modelos-base adotados para as simulações com as dimensões de dormitório (abertura de $15 \%$ da área do piso: $3,2 \times 1,8 \mathrm{~m}$ ) e estar (abertura de $25 \%$ da área do piso: 0,9×2,6 m)
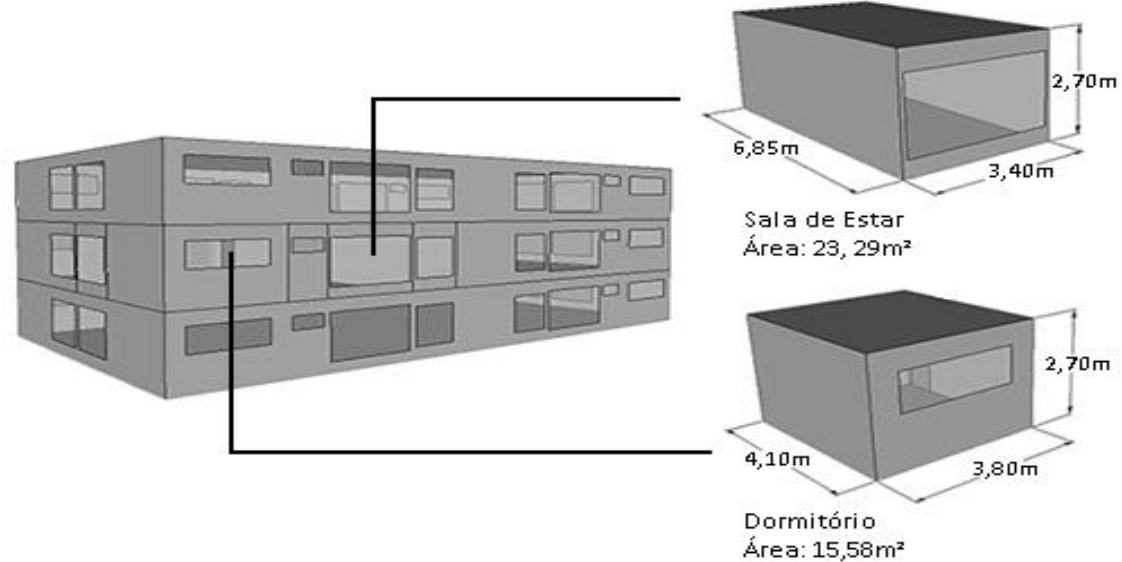

Fonte: adaptada de tipologia de LabEEE (2013).

\section{Figura 3 - Características das propriedades térmicas das envoltórias e cobertura}

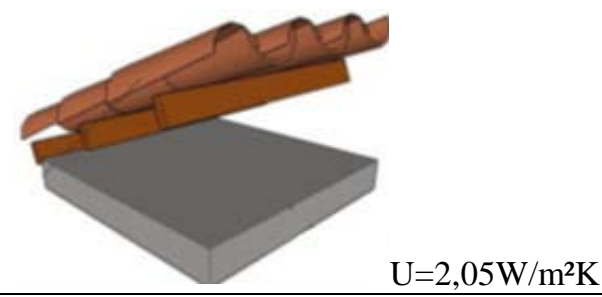

Cobertura de telha de barro com câmara de ar e laje de concreto. Espessura da telha: 1,0 cm. Espessura da laje: $12 \mathrm{~cm}$

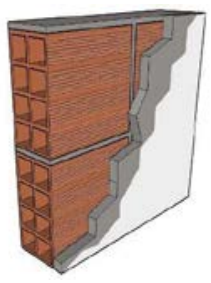

$\mathrm{U}=2 ., 39 \mathrm{~W} / \mathrm{m}^{2} \mathrm{~K}$ Parede de tijolos de 8 furos e assentados na menor dimensão. Dimensões do tijolo: 9,0 x 19,0 x 19,0 cm / espessura da argamassa assentamento: 1,0 cm / esp. da argamassa de emboço: $2,5 \mathrm{~cm}$ / esp. total da parede: $20,4 \mathrm{~cm}$

\begin{tabular}{|c|c|c|c|c|}
\hline Propriedades & Telha cerâmica & Laje concreto & $\begin{array}{c}\text { Composição } \\
\text { Alvenaria }\end{array}$ & $\begin{array}{c}\text { Argamassa } \\
\text { Reboco e } \\
\text { Embosso }\end{array}$ \\
\hline Calor específico(J/kg.K) & 920 & 920 & 540.4 & 1000 \\
\hline Densidade(kg/m3) & 2000 & 2200 & 950 & 2000 \\
\hline Condutividade $(\mathrm{w} / \mathrm{m} 2 . \mathrm{K})$ & 0,92 & 1,33 & 0,9 & 1,15 \\
\hline
\end{tabular}


Tabela 2 - Parâmetros construtivos de sistemas e rotinas de usos adotados pelas simulações

\begin{tabular}{|c|c|}
\hline Parâmetros & Definições adotadas nesta pesquisa \\
\hline Percentual de área envidraçada & $\begin{array}{l}\text { Dormitório - área de janela foi de } 15 \% \text { da área do piso. Estar - área de } \\
\text { janela foi de } 25 \% \text { da área do piso }\end{array}$ \\
\hline Percentual de ventilação & 45\% da área de janela do ambiente \\
\hline Características do vidro (cor, espessura) & Transparente, $3 \mathrm{~mm}$ \\
\hline Características das paredes e coberturas & Conforme indicado na Figura 3 \\
\hline Sistemas de sombreamento & Variados, conforme indicado na Tabela 3 \\
\hline $\begin{array}{l}\text { Iluminância artificial noturna no } \\
\text { dormitório e no estar }\end{array}$ & $100 \mathrm{~lx}$ \\
\hline Altura dos sensores de iluminação & $75 \mathrm{~cm}$ \\
\hline Densidade de potência instalada $\left(\mathrm{W} / \mathrm{m}^{2}\right)$ & Estar $=4,5 \mathrm{~W} / \mathrm{m}^{2}$, dormitório $=5 \mathrm{~W} / \mathrm{m}^{2}$ \\
\hline Padrão de uso de iluminação & $\begin{array}{l}\text { Por demanda, definido a partir das simulações de iluminação natural de } \\
\text { acordo com a necessidade de acionamento do sistema }\end{array}$ \\
\hline Densidade de equipamentos & $\begin{array}{l}\text { Estar: } 20,74 \mathrm{~W} \text { por período de ocupação; quarto: } 55,0 \mathrm{~W} \text { por período } \\
\text { de ocupação (aprox. } 1 \mathrm{~W} / \mathrm{m}^{2} \text { e } 4 \mathrm{~W} / \mathrm{m}^{2} \text { respectivamente) }\end{array}$ \\
\hline Taxas metabólicas & $\begin{array}{l}\text { Estar: sentado ou assistindo TV }=60 \mathrm{~W} / \mathrm{m}^{2} \text {; quarto: dormindo ou } \\
\text { descansando }=45 \mathrm{~W} / \mathrm{m}^{2} \text {; quarto: sentado ou estudando }=60 \mathrm{~W} / \mathrm{m}^{2}\end{array}$ \\
\hline Padrão de ocupação & Para semana e fins de semana, conforme indicado na Figura 4 \\
\hline Condicionamento térmico & $\begin{array}{l}\text { Ventilação natural com a abertura da janela ativada quando atingida } \\
\text { temperatura interna de } 20^{\circ} \mathrm{C} \text { - Abertura de } 50 \% \text { da área envidraçada }\end{array}$ \\
\hline
\end{tabular}

Figura 4 - Ocupação (horários e número de pessoas) de quartos, estar, cozinha e banheiro durante a semana e nos fins de semana

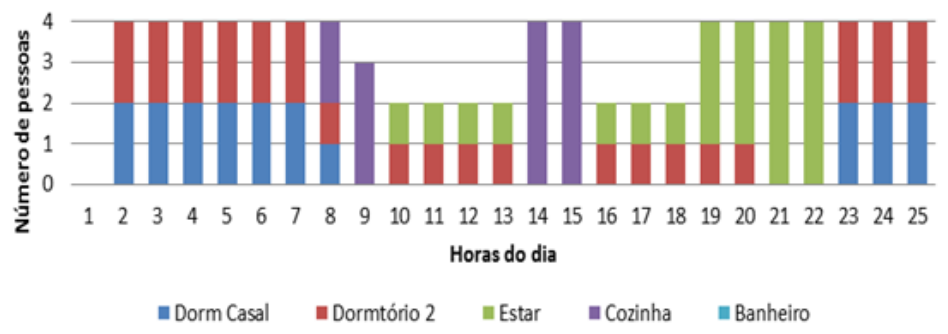

(1) Dias da Semana

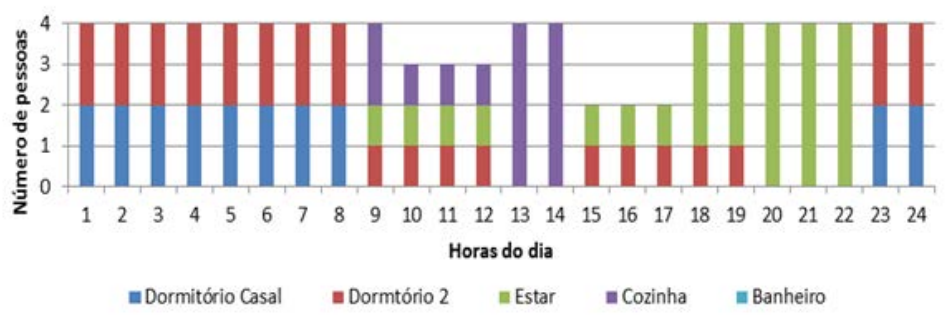

(2) Fim de Semana

O acionamento diferenciado das venezianas (VRTQR, V90 e V45) visou comparar os resultados entre o acionamento proposto no RTQ-R, que não leva em conta a presença do usuário e o acionamento devido ao comportamento do usuário ante o uso da luz natural.

O Daysim 3.0 integra a seu corpo um algoritmo comportamental chamado Lightswitch, elaborado a partir de pesquisas de campo em escritórios (REINHART; VOSS, 2003) que busca predizer as ações dos sistemas de controle de iluminação e de proteção solar do tipo persiana. Essas pesquisas levantaram a existência de dois tipos básicos de usuários: aqueles que acionam a iluminação ao entrarem no ambiente e deixam acionada mesmo quando deixam o ambiente por um curto período; e aqueles usuários que acionam a iluminação artificial apenas quando há baixos níveis de iluminância. Entre as conclusões dos estudos-base para a elaboração do Ligthswitch, Reinhart e Voss (2003) constataram que usuários utilizam a mesma estratégia de comportamento em relação ao acionamento da iluminação artificial e das persianas. Para o acionamento das persianas, os usuários também são definidos como ativo e passivo. O usuário passivo permanece com as persianas abaixadas durante todo o ano. Já o usuário 
ativo aciona as persianas quando há luz solar direta acima de $50 \mathrm{~W} / \mathrm{m}^{2}$ no plano de trabalho. O algoritmo Ligthswitch permite a simulação subhorária do uso da iluminação e da persiana, o que possibilita exportar um relatório de utilização dos sistemas em todas as horas do ano (BOURGEOIS; REINHART; MACDONALD, 2006). A partir dos relatórios dos sistemas de acionamento, o Daysim 3.0 gera automaticamente schedules (rotinas) horárias anuais de ocupação e cargas elétricas de iluminação e de acionamento da persiana/veneziana. Apesar de esses estudos terem sido feitos para ambientes de escritório, considerouse que uma pessoa estudando ou trabalhando em ambiente residencial seria responsável pelo mesmo tipo de acionamento das venezianas.

A Tabela 3 apresenta a metodologia usada para o dimensionamento das proteções solares fixas e a forma de acionamento das venezianas móveis. A geometria dos elementos de proteção solar foi definida de acordo com diferentes métodos para quatro orientações solares e para cada cidade analisada.

O modelo VRTQ-R foi utilizado para elaboração das equações do método prescritivo do RTQ-R e reproduzido nesta pesquisa com o intuito de gerar os graus-hora necessários para a pontuação igual a 1 para o Somb. Porém, é importante considerar que esse modelo pouco representa o comportamento de acionamento de venezianas por usuários. Os usuários tendem a abrir as venezianas durante a ocupação do ambiente e fechá-las apenas quando há desconforto por calor/radiação solar (REINHART; VOSS, 2003). Já as venezianas V90 (abertura máxima para iluminação) e V45 (área de abertura para iluminação de 45\%) são acionadas de acordo com os níveis de iluminância no ambiente interno.

A geometria das venezianas foi definida de acordo com as características da Figura 5.

\section{Simulação de iluminação}

As características do sistema de iluminação artificial são apresentadas na Figura 6. A iluminação artificial foi dimensionada para garantir uma iluminância de 100 lx. O valor adotado como referência para o dormitório e para o estar tomou como base a antiga NBR 5413 (ABNT, 1992), visto que a atual norma brasileira de iluminação artificial, a NBR 8995 (ABNT, 2013a), desenvolvida para ambientes de trabalho, não contempla usos residenciais.

As refletâncias das superfícies dos ambientes internos são apresentadas na Tabela 4.

O programa utilizado para a análise dinâmica da iluminação natural foi o Daysim 3.0, cujos resultados estabeleceram o padrão de acionamento da iluminação artificial. Neste estudo utilizou-se a métrica de autonomia de luz natural (dayligth autonomy) para verificar o atendimento ao nível mínimo de iluminância proveniente da luz natural. A malha de sensores foi localizada de acordo com o projeto luminotécnico a fim de se verificar a necessidade ou não do acionamento das luminárias projetadas. Para o ambiente de dormitório foi utilizado um sensor, localizado no centro do ambiente. Já para o ambiente de estar foram utilizados dois sensores, localizados no eixo longitudinal central do ambiente. Foi determinado um sistema com dois momentos de ativação: ligado ou desligado (on/off).

As simulações de iluminação natural foram feitas por tipo de ambiente, por orientação solar e por tipo de dispositivo de proteção. A rotina de acionamento das venezianas (V90 e V45) foi definida no Daysim como um modelo de sombreamento dinâmico simplificado, no qual o acionamento das venezianas acontece quando há brilho excessivo no plano de trabalho ou quando há valores de insolação direta acima de $50 \mathrm{~W} / \mathrm{m}^{2}$. Os modelos de sombreamento estático (L23, TN, PTI e PTF) foram definidos no Skecthup como parte do modelo 3D. Para o modelo de veneziana VRTQR, a rotina de acionamento das venezianas foi definida de acordo com a época do ano, conforme exposto por LabEEE (2011b). 
Tabela 3 - Descrição dos dispositivos simulados

\begin{tabular}{|c|c|c|c|}
\hline Cód. & Modelo & Tipologia & Descrição \\
\hline SP & & Sem proteção & $\begin{array}{l}\text { Base para investigar o impacto das proteções } \\
\text { nos ambientes em estudo. Modelo sem } \\
\text { dispositivos de proteção e, portanto, não } \\
\text { sujeito a pontuação pela variável Somb do } \\
\text { RTQ-R. }\end{array}$ \\
\hline VRTQR & (Venez & $\begin{array}{l}\text { Protótipo com } \\
\text { veneziana externa } \\
\text { definida de acordo } \\
\text { com o modelo } \\
\text { adotado para a } \\
\text { elaboração do RTQ-R }\end{array}$ & $\begin{array}{l}\text { Essas venezianas foram modeladas sempre } \\
\text { acionadas (fechadas) para as zonas } 6 \text { a } 8 \text { no } \\
\text { período de } 8 \text { h às } 18 \mathrm{~h} \text { e, para as zonas } 1 \text { a } 4 \text {, } \\
\text { fechadas no verão ( } 21 \text { de setembro a } 20 \text { de } \\
\text { março) e abertas durante o inverno ( } 21 \text { março } \\
\text { a } 20 \text { setembro) (LABORATÓRIO..., } 2011 \text { b). } \\
\text { A veneziana foi modelada no EnergyPlus } \\
\text { através do item Window material: Blind }\end{array}$ \\
\hline V90 & & $\begin{array}{l}\text { Protótipo com } \\
\text { veneziana com } \\
\text { abertura completa da } \\
\text { área }\end{array}$ & $\begin{array}{l}\text { Venezianas que apresentam envidraçamento } \\
\text { em toda a área do vão da abertura com quatro } \\
\text { folhas, sendo duas compostas por venezianas } \\
\text { e duas envidraçadas. Acionamento } \\
\text { determinado pelo algoritmo Ligthswitch do } \\
\text { Daysim. }\end{array}$ \\
\hline V45 & (Venezia & $\begin{array}{l}\text { Protótipo com } \\
\text { veneziana com } \\
\text { abertura de até } 45 \% \\
\text { da área }\end{array}$ & $\begin{array}{l}\text { Apresenta envidraçamento de } 45 \% \text { do vão da } \\
\text { abertura, ou seja, o restante fechado por } \\
\text { veneziana. Caracterizada por três folhas, } \\
\text { sendo duas compostas de venezianas e uma } \\
\text { envidraçada. O acionamento dessa veneziana } \\
\text { foi determinado pelo algoritmo Ligthswitch } \\
\text { do Daysim, assim como a V90. }\end{array}$ \\
\hline L23 & & $\begin{array}{l}\text { Protótipo com } \\
\text { dispositivos de } \\
\text { proteção solar } \\
\text { horizontais definidos } \\
\text { pelo método das } \\
\text { latitudes do RTQ-R }\end{array}$ & $\begin{array}{l}\text { Este protótipo foi baseado no texto do RTQ-R } \\
\text { que objetiva uma maneira simplificada de } \\
\text { mensurar o sombreamento realizado por } \\
\text { varandas, beirais e brises horizontais, } \\
\text { podendo alcançar valores de Somb de até } 0,2 \text {. }\end{array}$ \\
\hline TN & & $\begin{array}{l}\text { Protótipo com } \\
\text { dispositivos de } \\
\text { proteção solar } \\
\text { segundo o método do } \\
\text { Anexo } 1 \text { do RTQ-R }\end{array}$ & $\begin{array}{l}\text { Este protótipo foi definido a partir do } \\
\text { dimensionamento das proteções pelo método } \\
\text { de avaliação do Anexo } 1 \text { do RTQ-R, podendo } \\
\text { alcançar valores de Somb de até } 0,5 \text {. }\end{array}$ \\
\hline PTI & & $\begin{array}{l}\text { Protótipo com } \\
\text { dispositivo } \\
\text { dimensionado para } \\
\text { sombreamento entre } \\
7 \text { h40 e } 16 h 20 \\
\text { (aproxim. } 70 \% \text { das } \\
\text { horas de insolação) - } \\
\text { Placa inteira }\end{array}$ & $\begin{array}{l}\text { O protótipo PTI foi idealizado para que não } \\
\text { houvesse insolação incidente na abertura } \\
\text { entre } 7 \text { h } 40 \text { e } 16 \text { h20, de acordo com o horário } \\
\text { proposto por Guedes (2012). Foi prevista uma } \\
\text { composição de placas inteiras horizontais e } \\
\text { verticais. }\end{array}$ \\
\hline PTF & & $\begin{array}{l}\text { Protótipo com } \\
\text { dispositivo de } \\
\text { proteção solar para } \\
\text { sombreamento das } \\
7 \text { h40 às } 16 h 20 \text { ( } 70 \% \\
\text { das horas de } \\
\text { insolação) - Placas } \\
\text { filetadas }\end{array}$ & $\begin{array}{l}\text { Este protótipo é caracterizado da mesma } \\
\text { forma que o anterior. Porém, neste caso, } \\
\text { procurou-se filetar as proteções a fim de } \\
\text { investigar a influência da forma do } \\
\text { dispositivo e o impacto de maiores } \\
\text { superfícies refletivas quanto ao desempenho } \\
\text { térmico e luminoso. }\end{array}$ \\
\hline
\end{tabular}


Figura 5 - Características da veneziana adotada nas simulações

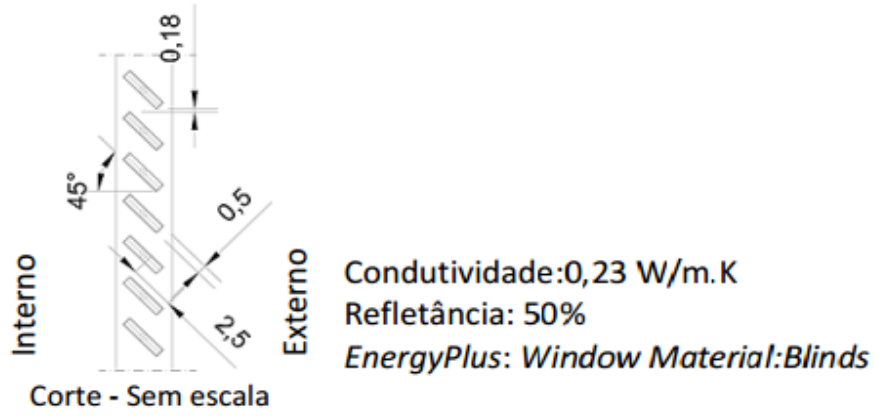

Figura 6 - Parâmetros do projeto luminotécnico, carga de ocupação e pontos de distribuição de iluminação na sala de estar e dormitório

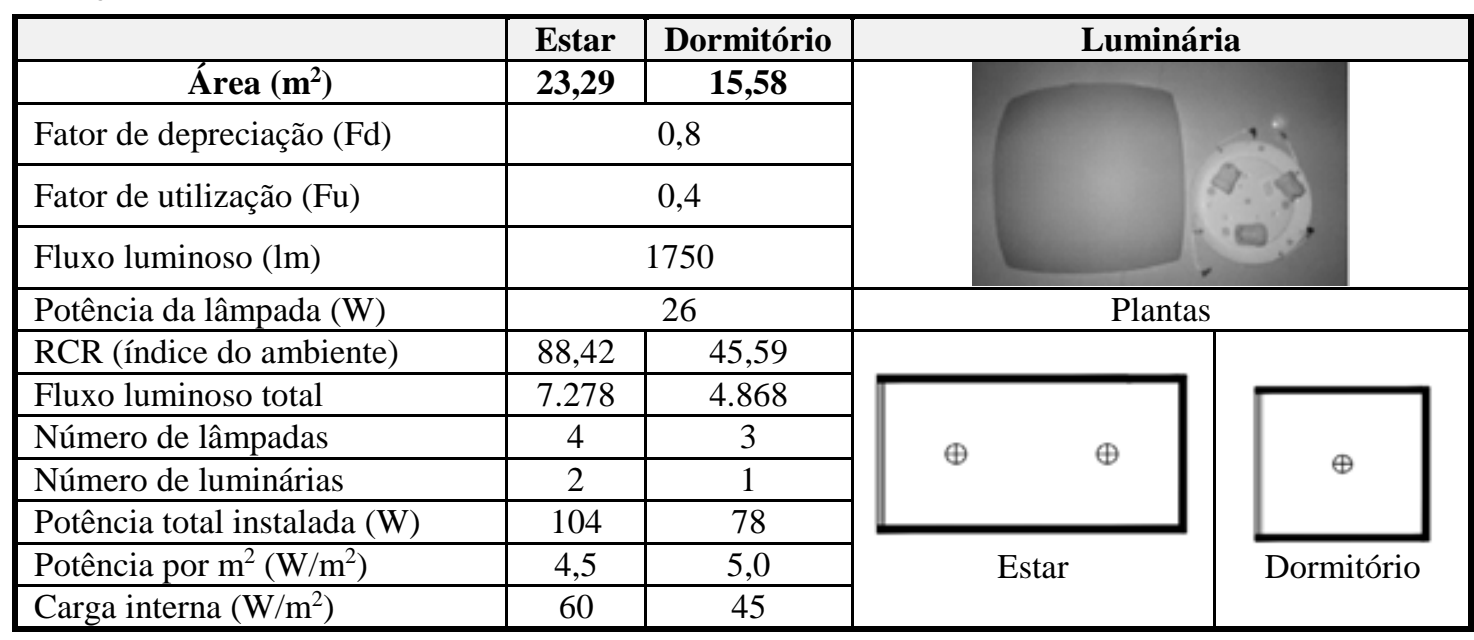

Tabela 4 - Refletância da superfície dos materiais adotados

\begin{tabular}{c|c}
\hline Superfície & Refletância (\%) \\
\hline Pisos & 20 \\
Tetos & 70 \\
Paredes & 50 \\
Alpendre & 25 \\
\hline
\end{tabular}

Fonte: adaptada de Steffy (1990 ${ }^{1}$ apud SOUZA, 2003).

Para a simulação de venezianas foi utilizada a configuração sugerida por Reinhart (2010), apresentada nas Tabelas 5 e 6.

\section{Simulação térmica}

As simulações térmicas foram realizadas com o uso do software EnergyPlus versão 7.2. Os modelos foram variados por orientação solar das aberturas e por tipo dos dispositivos de sombreamento.

Para verificar o desempenho de ambientes, foram solicitados dados de saída das simulações relativos a sua temperatura operativa. Foram gerados indicativos de graus-hora de resfriamento e aquecimento para cada modelo, em cada zona bioclimática e orientações solares estudadas.

Os graus-hora de resfriamento (GHR) são determinados como a somatória da diferença da temperatura horária quando esta se encontra superior à temperatura de base de resfriamento. Os graus-hora de aquecimento (GHA) são determinados pela somatória da diferença da temperatura operativa horária quando esta se encontra inferior à temperatura de base para aquecimento.

${ }^{1}$ STEFFY, G. R. Architectural Lighting Design. New York: Van Nostrand Reinhold Company, 1990. 
Tabela 5 - Complexidade da cena para modelos sem elementos de proteção solar

\begin{tabular}{c|c|c|c|c|c|c}
\hline $\begin{array}{c}\text { Ambient } \\
\text { Bounces }\end{array}$ & $\begin{array}{c}\text { Ambient } \\
\text { Division }\end{array}$ & $\begin{array}{c}\text { Ambient } \\
\text { Sampling }\end{array}$ & $\begin{array}{c}\text { Ambiente } \\
\text { Accuracy }\end{array}$ & $\begin{array}{c}\text { Ambient } \\
\text { Resolution }\end{array}$ & $\begin{array}{c}\text { Direct } \\
\text { Threshold }\end{array}$ & $\begin{array}{c}\text { Direct } \\
\text { Sampling }\end{array}$ \\
\hline 5 & 1.000 & 20 & 0,1 & 300 & 0 & 0 \\
\hline
\end{tabular}

Fonte: adaptado de Reinhart (2010).

Tabela 6 - Complexidade da cena para modelos com elementos de proteção solar

\begin{tabular}{c|c|c|c|c|c|c}
\hline $\begin{array}{c}\text { Ambient } \\
\text { Bounces }\end{array}$ & $\begin{array}{c}\text { Ambient } \\
\text { Division }\end{array}$ & $\begin{array}{c}\text { Ambient } \\
\text { Sampling }\end{array}$ & $\begin{array}{c}\text { Ambiente } \\
\text { Accuracy }\end{array}$ & $\begin{array}{c}\text { Ambient } \\
\text { Resolution }\end{array}$ & $\begin{array}{c}\text { Direct } \\
\text { Threshold }\end{array}$ & $\begin{array}{c}\text { Direct } \\
\text { Sampling }\end{array}$ \\
\hline 7 & 1.500 & 100 & 0,1 & 300 & 0 & 0 \\
\hline
\end{tabular}

Fonte: adaptada de Reinhart (2010).

Os graus-hora geralmente são calculados para as temperaturas do ar, porém neste trabalho são indicados para as temperaturas operativas. As temperaturas operativas foram calculadas conforme LabEEE (LABORATÓRIO..., 2011b), cujos limites de conforto para a temperatura operativa foram obtidos a partir dos critérios da ISO 7730:2005 para atividades leves $\left(70 \mathrm{~W} / \mathrm{m}^{2}\right)$.

Para as condições de verão, período de resfriamento, foi considerado isolamento térmico das roupas de 0,5 clo, e a temperatura operativa entre $23^{\circ} \mathrm{C}$ e $26^{\circ} \mathrm{C}$. Para as condições de inverno, período de aquecimento, foi considerado isolamento térmico das roupas de 1,2 clo, e temperatura operativa entre $18{ }^{\circ} \mathrm{C}$ e $22^{\circ} \mathrm{C}$. Sendo assim, a temperatura-base para o cálculo de graushora de resfriamento foi de $26^{\circ} \mathrm{C}$, e a temperaturabase para o cálculo de graus-hora de aquecimento foi de $18^{\circ} \mathrm{C}$.

O modelo sem sombreamento (SP) foi caracterizado como caso-base, determinado para cada orientação solar e zona bioclimática. A partir de cada caso-base foram gerados percentuais de ganho ou diminuição de graus-hora, de resfriamento e de aquecimento. Esses percentuais gerados a partir da diferença entre os graus-hora Resf+Aquec do modelo avaliado e os graus-hora Resf+Aquec do modelo sem proteção foram divididos pelos graushora Resf+Aquec resultantes do modelo sem proteção, de acordo com a Equação 2:

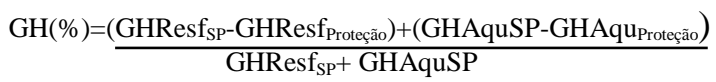

Os resultados percentuais relativos ao desempenho dos modelos foram determinados a partir de uma média ponderada entre os casos dos ambientes de dormitório e de estar. Essa média permite estimar um desempenho intermediário entre um ambiente profundo (estar) e um ambiente pouco profundo (dormitório).

\section{Procedimento de avaliação da variável Somb}

Mediante simulações computacionais realizadas, foi proposta uma escala única para pontuação dos dispositivos de sombreamento. Essa escala foi construída a partir dos resultados da simulação dos ambientes condicionados naturalmente, considerando o desempenho do modelo sem proteção (SP) com pontuação 0 (zero), e o desempenho do modelo com veneziana, VRTQR (simulado de acordo com o modelo utilizado para elaboração das equações do RTQ-R), com pontuação 1 (um). Os dispositivos receberam, então, pontuações com valores entre 0 e 1 , ou superiores a 1 quando demonstrado desempenho superior ao modelo VRTQR. Para a avaliação dos resultados foram gerados gráficos que mostram as pontuações de cada modelo por zona bioclimática e orientação a partir dos resultados de graus-hora. A pontuação final do dispositivo foi determinada como sendo a média ponderada das pontuações do ambiente de dormitório e de estar.

\section{Análise e discussão de resultados}

\section{Dimensionamento de dispositivos}

Os dispositivos de proteção foram dimensionados em sete zonas bioclimáticas e quatro orientações. A Tabela 7 mostra as máscaras das proteções solares para Salvador, ZB8, do tipo TN (método do Anexo 1 do RTQ-R), L23 ( $2^{\circ}$ método de dimensionamento do RTQ-R), PTI e PTF.

A Tabela 8 apresenta os ângulos usados para o dimensionamento das proteções solares para cada uma das orientações e zonas bioclimáticas analisadas.

Ao comparar os métodos de dimensionamento entre si, verifica-se que o método de sombreamento dos modelos PTI e PTF (proteções propostas para gerar 
sombreamento total das aberturas durante o dia) apresentou os maiores elementos, o que é natural, pois este método pretende evitar parte significativa da insolação direta nos ambientes internos.

Já o modelo L23, que possui dimensionamento simplificado, apresentou os menores sombreamentos para todas as zonas bioclimáticas. Esse método não pontua o sombreamento para sul nas zonas bioclimáticas de 1 a 3 e apresenta uma exigência de ângulo de $45^{\circ}$ para orientações leste e oeste para todas as ZB. Os métodos PTI e PTF apresentam ângulos de $75^{\circ}$ a $80^{\circ}$ para pontuação dos elementos para essas orientações.

Para o método TN, por apresentar duas opções de conjuntos de ângulos para determinar o sombreamento da abertura, foi escolhida a opção que mais se aproximava da tipologia desenvolvida para os demais métodos. É importante ressaltar que este método, para não se tornar exigente demais em seus critérios de pontuação, não pontua 0 sombreamento nas zonas bioclimáticas de 1 a 3 para as orientações norte, sul e leste, apesar de haver insolação direta nessas fachadas.

Tabela 7 - Exemplo de máscaras solares para a zona bioclimática 8 (Salvador)

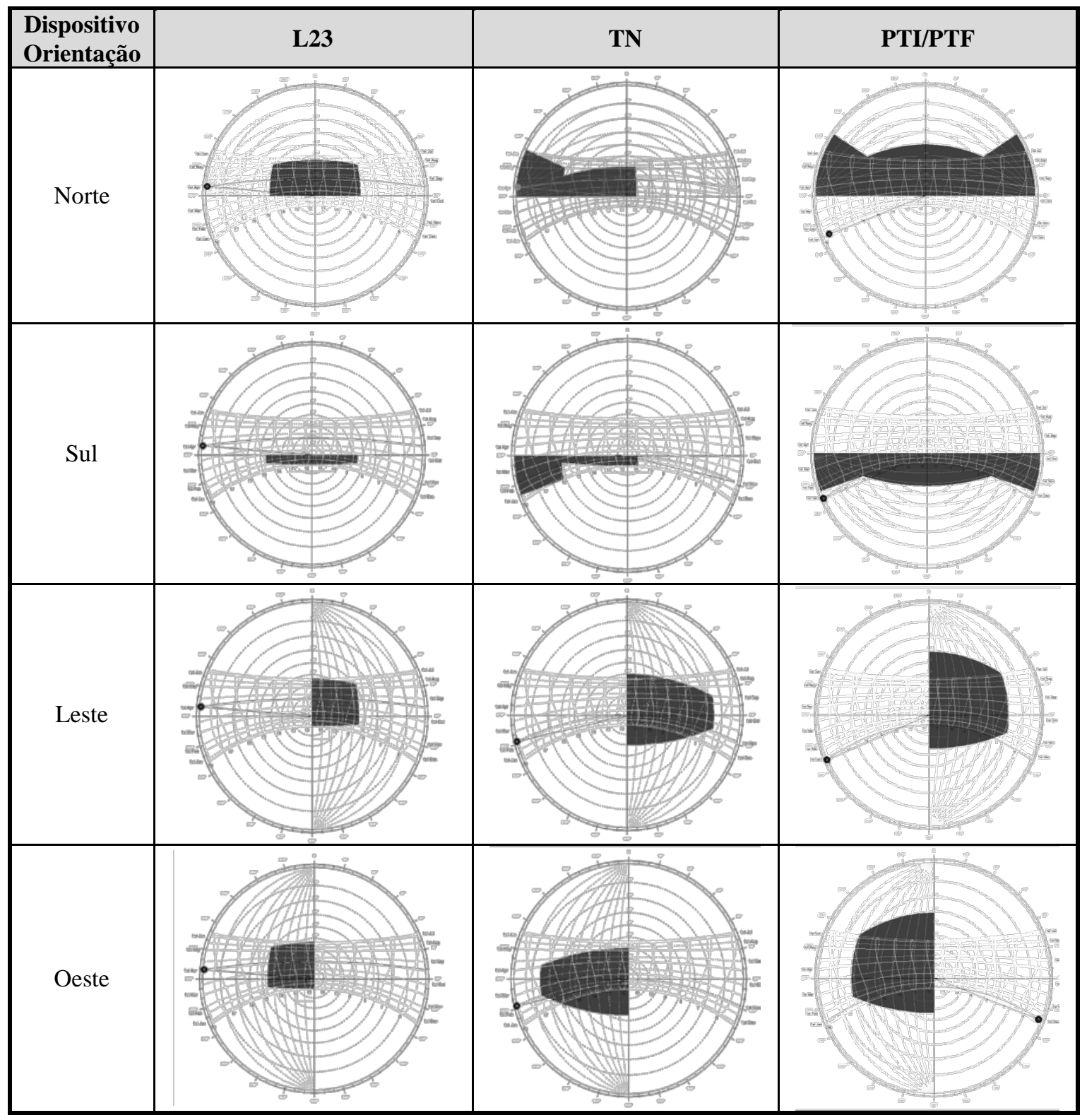


Tabela 8 - Resumo do dimensionamento dos dispositivos de proteção solar desenvolvidos pelos métodos TN(método da temperatura neutra), L23(método da latitude), PTI (proteção total com placas inteiras) e PTF (proteção total com placas filetadas)

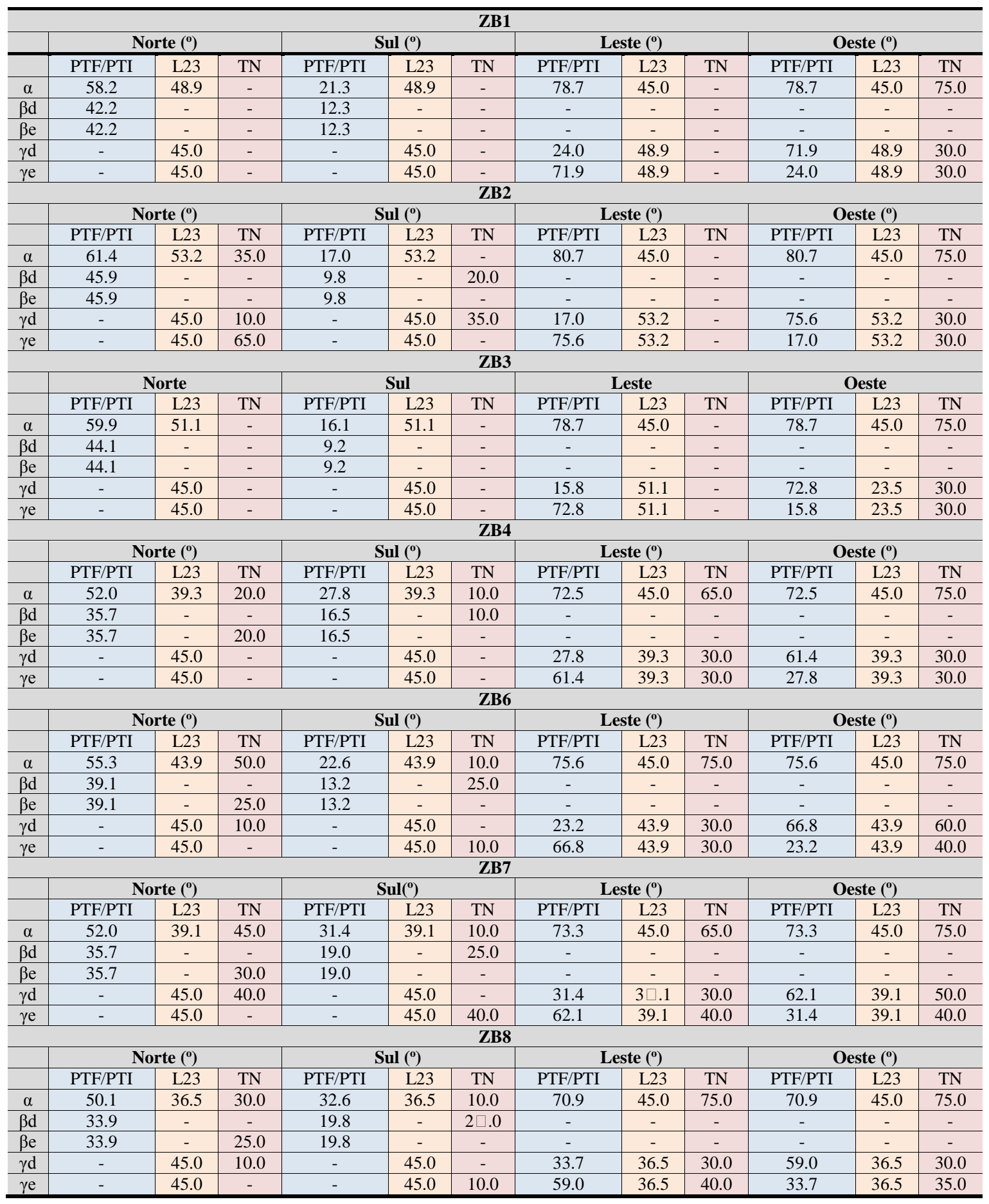

Nota: Legenda:

a - ângulo de proteção horizontal;

Bd - ângulo de proteção vertical à direita;

Be - ângulo de proteção vertical à esquerda;

Yd - ângulo de extensão da proteção horizontal à direita; e

ye - ângulo de extensão da proteção horizontal à esquerda. 
A Figura 7 apresenta o resultado médio do acionamento (fechamento) das venezianas VRTQR, V45 e V90. Pelos resultados gerais, percebe-se que as venezianas V90 e V45 apresentaram pouco ou nenhum acionamento para todas as zonas e orientações. Apenas para a orientação oeste percebe-se um acionamento maior, alcançando valores de até $21 \%$ das horas ocupadas. Para sul, apenas o modelo VRTQR apresentou acionamento nas horas ocupadas pois é um modelo fechado ao longo do dia durante o verão para as zonas bioclimáticas de 1 a 4, e durante todo o ano para as zonas 5 a 8, de acordo com as indicações do RTQR.

Figura 7 - Percentual médio de acionamento (a veneziana é fechada) das venezianas do tipo VRTQR, V45 e V90 para todas as zonas bioclimáticas avaliadas
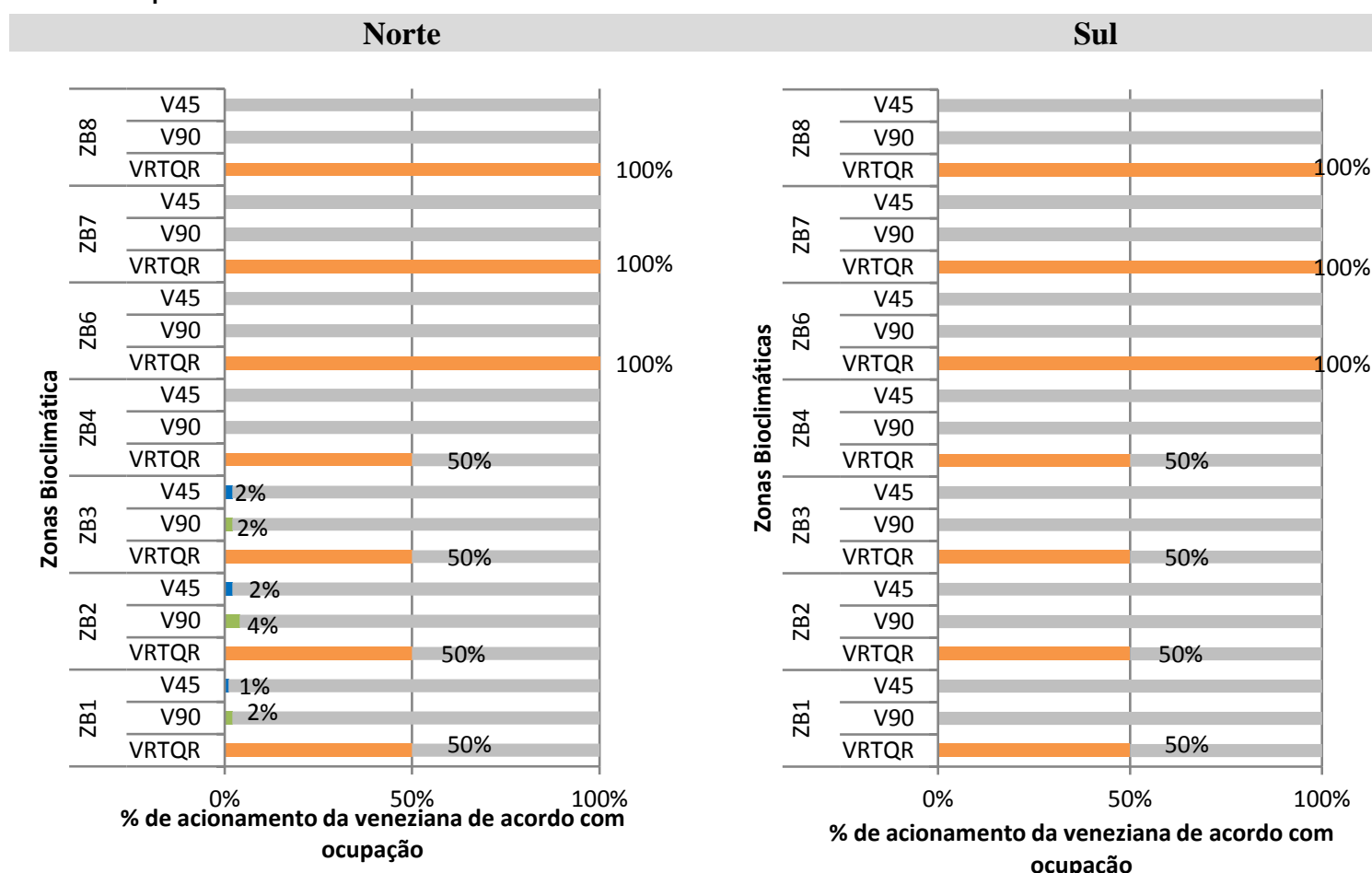

Leste ocupação

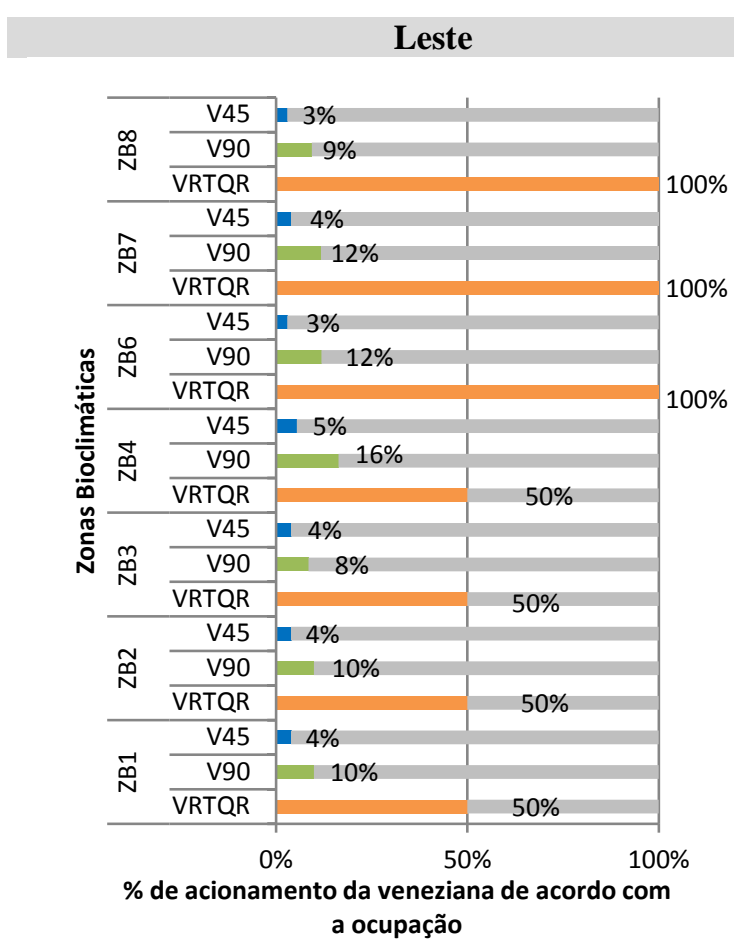

Oeste

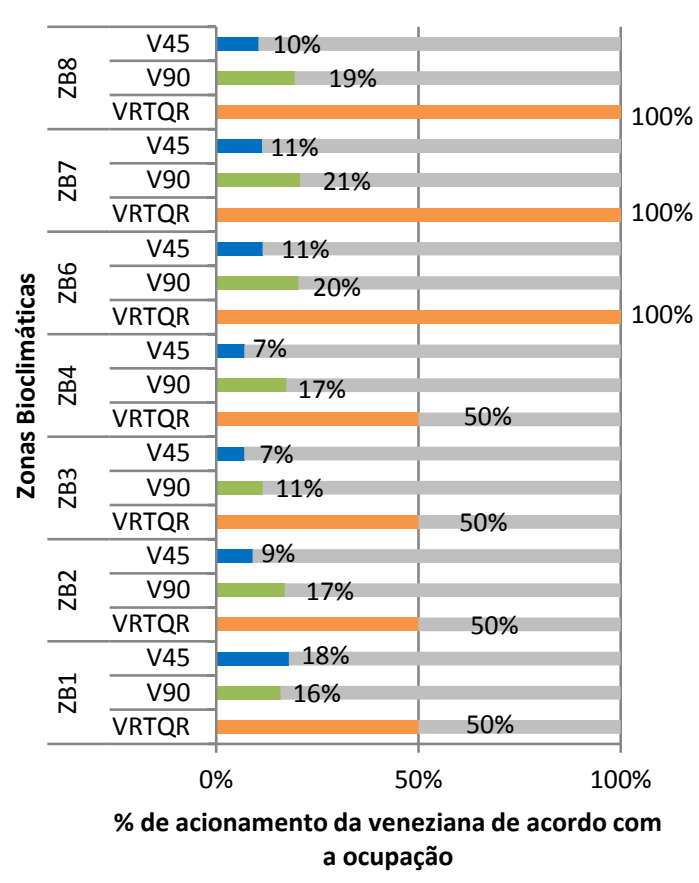




\section{Porcentagem de acionamento da iluminação artificial}

Para investigação do impacto dos elementos de proteção no comportamento da iluminação natural nos ambientes, foi calculada a porcentagem de horas de acionamento de luz artificial durante o dia ao longo do ano para os ambientes analisados para as quatro orientações solares e para todas as zonas bioclimáticas.

A Figura 8 representa a variação das porcentagens máximas, médias e mínimas de horas de acionamento da iluminação artificial para as zonas bioclimáticas avaliadas e orientações norte, sul, leste e oeste. Essa percentagem é uma média entre os dois sensores da sala e o sensor do quarto.

Verificou-se que o modelo VRTQR, ao manter as venezianas fechadas ao longo do dia no verão de algumas $\mathrm{ZB}$, apresenta naturalmente os piores desempenhos em relação à integração com a luz natural. Para os demais casos, verifica-se que os modelos de sombreamento mais robustos, como o PTF, apresentaram maior necessidade de acionamento do sistema de iluminação artificial para todas as zonas e orientações solares, com exceção da orientação sul, na qual os elementos são menores e permitem maior entrada de luz difusa nos ambientes.

\section{Desempenho térmico com o uso de dispositivos de proteção solar}

Foi calculada a redução percentual média de graushora para resfriamento e aquecimento em relação ao modelo sem proteção (SP) do uso de dispositivos de proteção solar no dormitório e para as orientações norte, sul, leste e oeste nas zonas bioclimáticas ZB1, ZB2, ZB3, ZB4, ZB6, ZB7 e ZB8, apresentada na Figura 9.

Em geral, observa-se que um mesmo modelo de proteção solar possui potencial diferenciado de redução de graus-hora considerando as diferentes zonas bioclimáticas e que apenas a zona bioclimática 1 apresenta aumento do número de graus-hora quando do uso de elementos de sombreamento nas aberturas (nas fachadas norte e leste). Isso era esperado porque esta é uma zona de clima predominantemente frio, na qual a insolação é bem-vinda em boa parte do ano.

Figura 8 - Porcentagem de horas de acionamento da iluminação artificial por orientação solar com o uso de dispositivos de proteção solares variados considerando todas as zonas bioclimáticas avaliadas

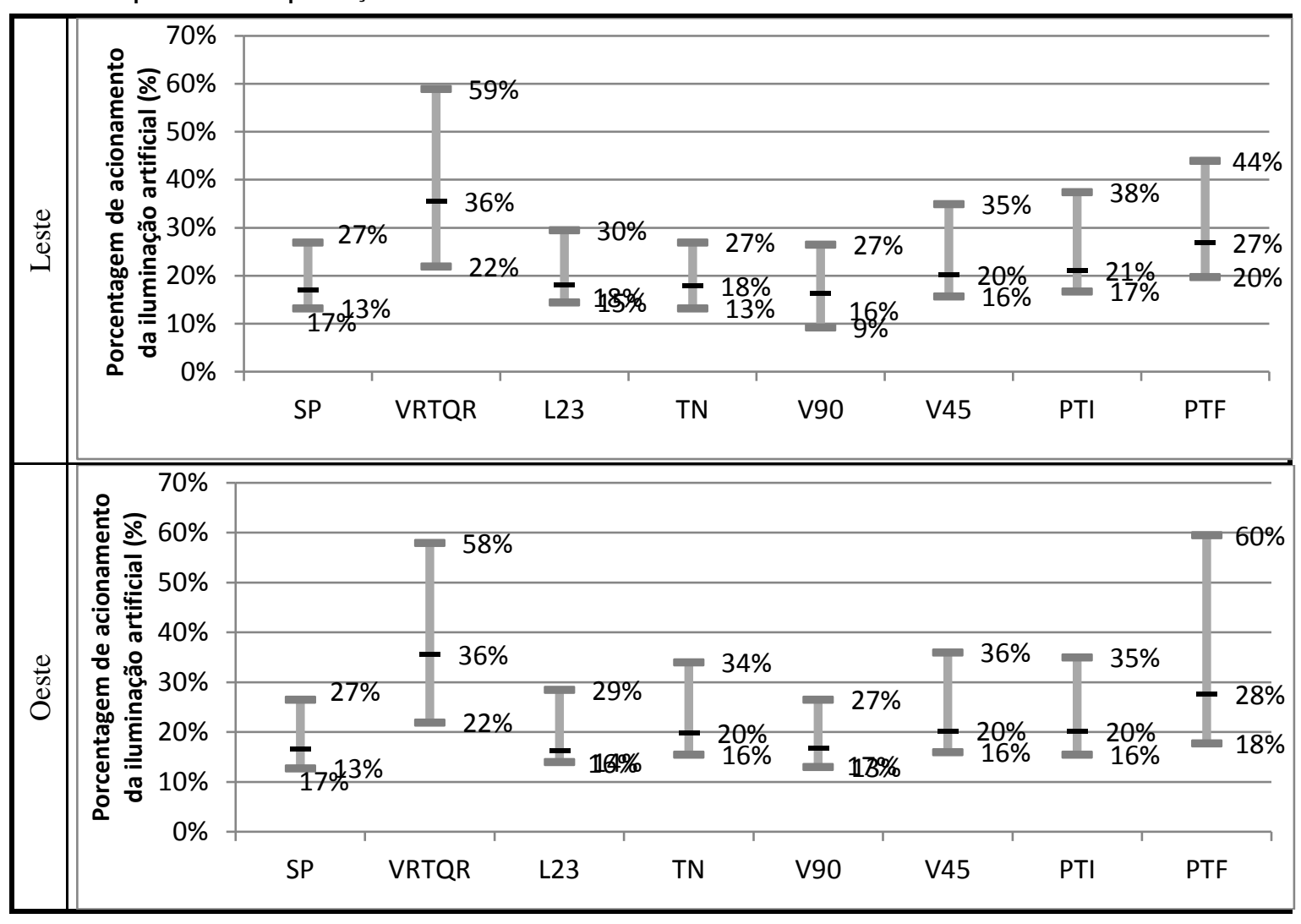


Figura 9 - Redução percentual média entre dormitório e estar de graus-hora para resfriamento e aquecimento com o uso de dispositivos de proteção solares comparados ao caso sem proteção solar

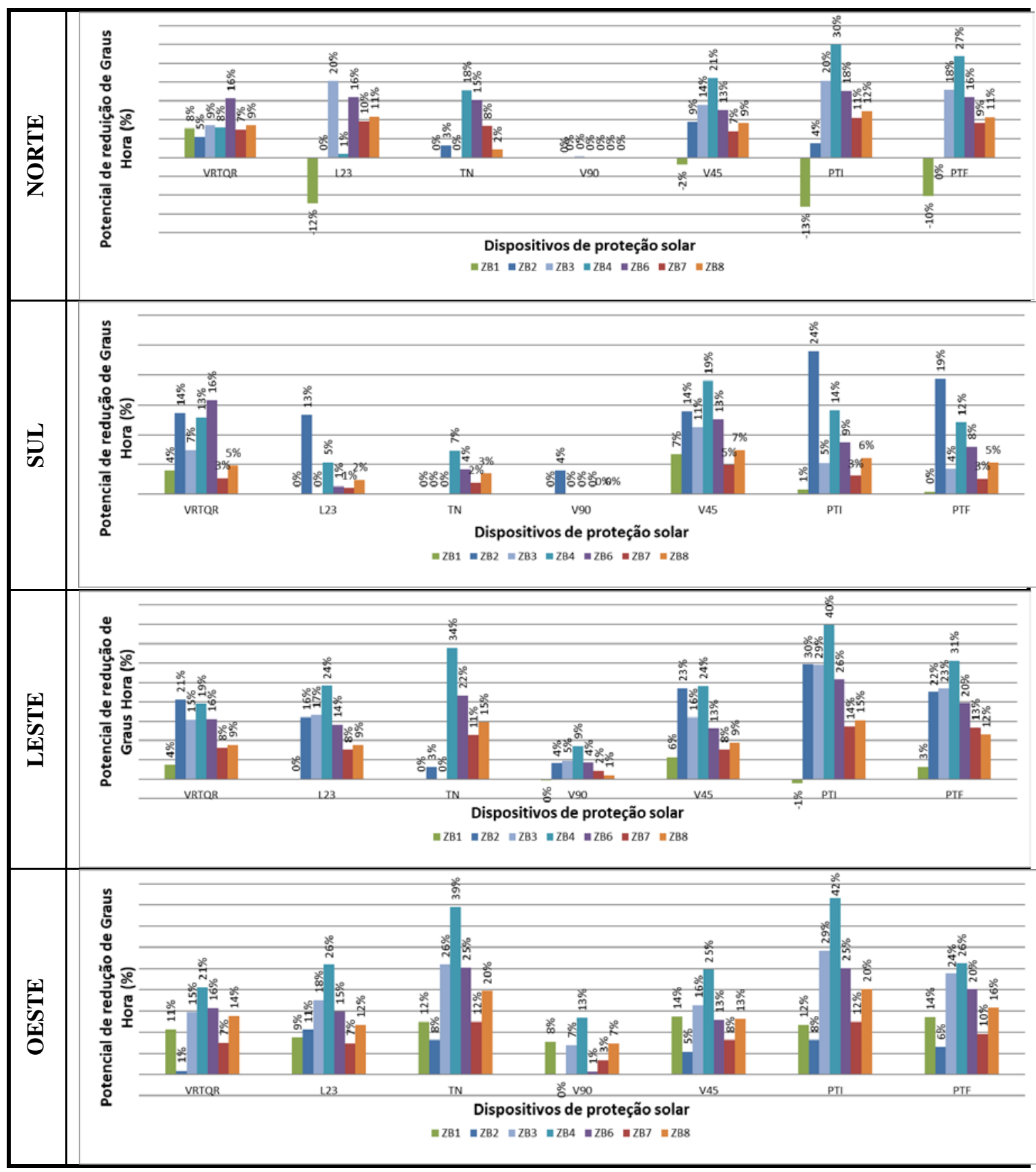

Notas: VRTQR (veneziana com acionamento no período de verão para as zonas 1 a 4 e sempre acionada para as demais zonas); L23 (dispositivo horizontal dimensionado de acordo com RTQ-R - Método das Latitudes); venezianas do tipo V45 (área de abertura para iluminação de 45\%) e V90 (abertura máxima para iluminação); dispositivos externos PTI (placas inteiras) e PTF (placas filetadas).

É possível observar que as maiores reduções de graus-hora são relativas aos modelos PTI, PTF e TN, seguidos pelos desempenhos de L23 e V45. Para a orientação norte, os modelos PTI, PTF e L23 apresentaram as maiores reduções. Para a orientação sul, a venezianas foram os modelos com melhor desempenho - dispositivos V45 e V90. Já para a orientação leste e oeste, os modelos PTI, PTF e TN apresentaram os melhores desempenhos. Contudo, para leste, nota-se que o modelo TN só conquistou bons desempenhos para as zonas bioclimáticas de clima quente, onde é prevista pontuação para a existência de sombreamento.

De um modo geral, pôde-se constatar que as proteções solares fixas apresentaram maior redução no número de graus-hora, com exceção da 
orientação sul, e que as venezianas VRTQ-R e V45 tenderam a apresentar desempenho semelhante. Isso se justifica porque, enquanto a VRTQ-R fica totalmente fechada durante parte do ano, a V45 fica sempre com uma folha fechada, o que, na média, gera resultados mais próximos.

Esperava-se que as proteções do tipo PTF (brises filetados, por exemplo) apresentassem melhor desempenho luminoso e térmico se comparadas às proteções de apenas uma placa (varandas, por exemplo) devido à interreflexão entre as aletas no caso da luz natural. Tal expectativa, no entanto, não se mostrou verdadeira em ambos os casos, tendo as PTI melhor desempenho em geral se comparadas às PTF.

\section{Avaliação do sistema de pontuação dos dispositivos de sombreamento pelo RTQ-R}

A partir da redução do número de graus-hora foi calculado o desempenho de cada sistema de sombreamento analisado em relação ao desempenho obtido pela VRTQR, que permite pontuação igual a 1 no RTQ-R.

Para cada zona bioclimática foi feita a média do desempenho entre dormitório e estar. De forma que se possa visualizar a variação de pontuação obtida para o Somb entre dormitório e estar, a Figura 10 apresenta os resultados obtidos para a zona bioclimática 3 para todas as fachadas. $\mathrm{O}$ desempenho de graus-hora varia entre quarto e dormitório em função de cada tipologia.

Pode-se verificar pelas pontuações obtidas que para a ZB1 que, de modo geral, os dispositivos de proteção solar que apresentam desempenho negativo na fachada norte não interferem significativamente na fachada sul e são uma estratégia mais interessante na fachada oeste.

Figura 10 - Escala de pontuação da variável Somb para a zona bioclimática 1 para aberturas com dispositivos L23, TN, V90, V45, PTI, PTF para dormitório, estar e média

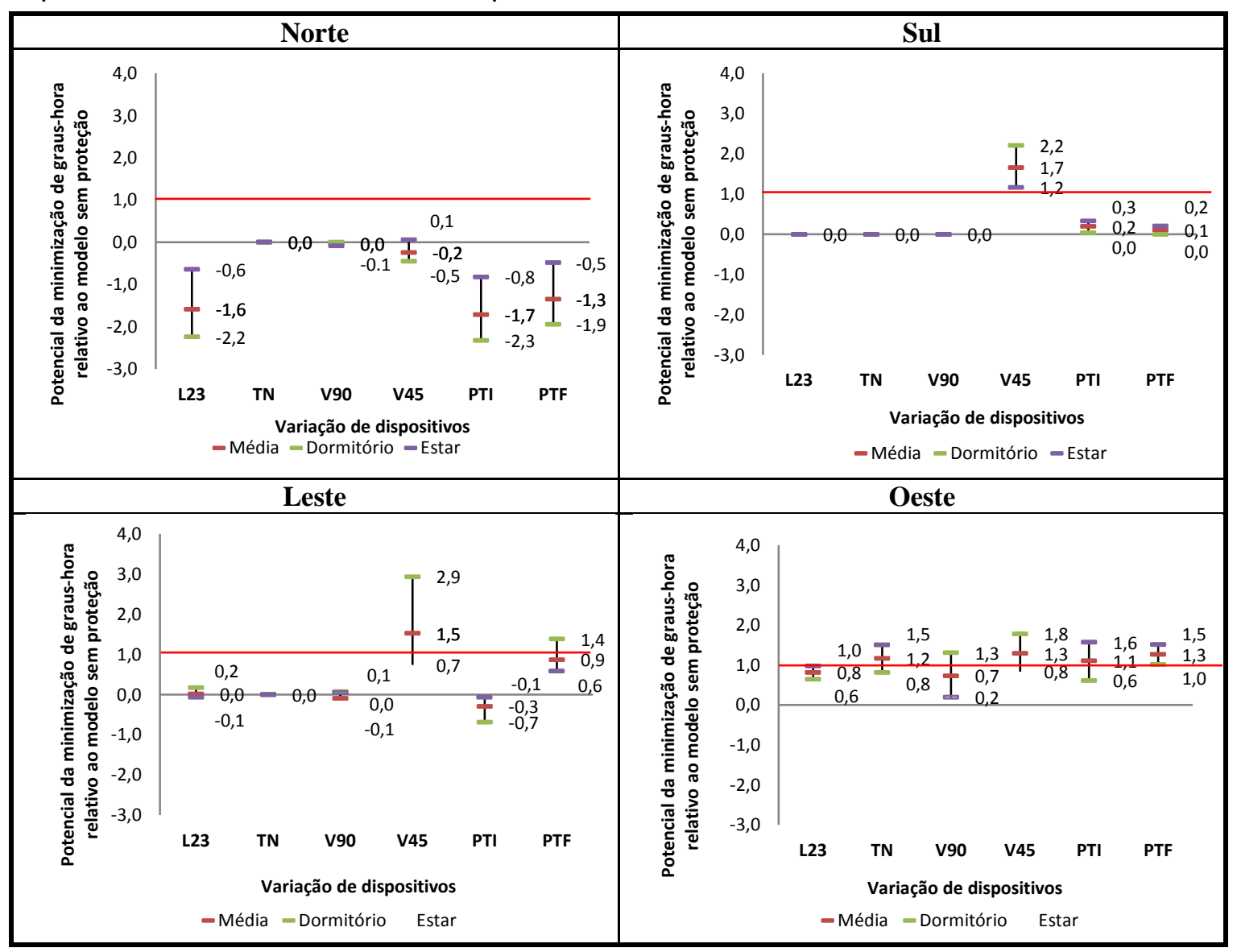


A Tabela 9 apresenta a média das pontuações da variável Somb obtidas para todas as zonas bioclimáticas. Os modelos sem proteção (SP) receberam pontuação 0 , e o modelo VRTQR recebeu pontuação 1 . Observa-se ainda que os modelos L23, TN e V90, quando não apresentaram dispositivo de sombreamento, receberam a pontuação 0 .

Verifica-se por essa tabela que os modelos PTI, PTF, V45 e TN para algumas orientações apresentaram desempenhos bastante superiores ao do modelo VRTQR. Ou seja, brises, varandas e toldos podem apresentar desempenho térmico igual ou superior ao das venezianas, com valores maiores que os indicados nos métodos para pontuação desses dispositivos (de 0,2 ou de 0,5 no máximo), o que indica que o regulamento efetivamente tende a subestimar o potencial de aumento de desempenho desses elementos. O modelo L23, que receberia a nota 0,2 para todas as orientações quando avaliado pelo método do RTQ-R, é pontuado de -1,6 a 2,4. Os dispositivos PTI, PTF e TN, que receberiam pontuação de até 0,5 pelo RTQ-R pelo presente método de análise, pontuariam de $-1,7$ a 3,8 . Isso parece demonstrar que as pontuações máximas de 0,2 e 0,5 dadas ao Somb calculadas pelo método da latitude e pelo método do Anexo 1 do RTQ-R (INSTITUTO..., 2012) estão subdimensionadas.

Já com as venezianas V45 e V90, as quais pontuam o valor máximo pelo RTQ-R, nota-se uma grande variação nos resultados das simulações, com pontuações de $-0,2$ a 2,7, o que indica que o desenho e o acionamento delas influem no desempenho térmico dos ambientes.

Tabela 9 - Escala pontuação média entre dormitório e estar da variável Somb em todas as zonas bioclimáticas para aberturas com dispositivos variáveis dimensionados para sombrear o período de $7 \mathrm{~h} 40$ às $16 \mathrm{~h} 20$

\begin{tabular}{|c|c|c|c|c|c|c|c|c|}
\hline ZB1 & SP & VRTQR & L23 & $\mathrm{TN}$ & V90 & V45 & PTI & PTF \\
\hline Norte & 0,00 & 1,00 & $-1,59$ & 0,00 & $-0,03$ & $-0,24$ & $-1,71$ & $-1,35$ \\
\hline Sul & 0,00 & 1,00 & 0,00 & 0,00 & 0,00 & 1,66 & 0,20 & 0,11 \\
\hline Leste & 0,00 & 1,00 & 0,02 & 0,00 & $-0,09$ & 1,53 & $-0,29$ & 0,87 \\
\hline Oeste & 0,00 & 1,00 & 0,82 & 1,17 & 0,73 & 1,29 & 1,11 & 1,27 \\
\hline ZB2 & SP & VRTQR & L23 & $\mathrm{TN}$ & V90 & V45 & PTI & PTF \\
\hline Norte & 0,00 & 1,00 & 2,25 & 1,89 & 0,01 & 1,58 & 2,15 & 1,93 \\
\hline Sul & 0,00 & 1,00 & 0,00 & 0,60 & 0,00 & 1,73 & 0,71 & $-0,01$ \\
\hline Leste & 0,00 & 1,00 & 0,97 & 0,00 & 0,29 & 1,01 & 1,76 & 1,41 \\
\hline Oeste & 0,00 & 1,00 & 1,08 & 1,61 & 0,53 & 1,05 & 1,84 & 1,57 \\
\hline ZB3 & SP & VRTQR & L23 & TN & V90 & V45 & PTI & PTF \\
\hline Norte & 0,00 & 1,00 & 2,38 & 0,00 & 0,03 & 1,64 & 2,39 & 2,11 \\
\hline Sul & 0,00 & 1,00 & 0,00 & 0,00 & 0,00 & 1,52 & 0,71 & 0,58 \\
\hline Leste & 0,00 & 1,00 & 1,07 & 0,00 & 0,30 & 1,03 & 1,91 & 1,51 \\
\hline Oeste & 0,00 & 1,00 & 1,19 & 1,77 & 0,47 & 1,12 & 1,99 & 1,62 \\
\hline ZB4 & SP & VRTQR & L23 & $\mathrm{TN}$ & V90 & V45 & PTI & PTF \\
\hline Norte & 0,00 & 1,00 & 0,12 & 2,28 & 0,00 & 2,70 & 3,84 & 3,44 \\
\hline Sul & 0,00 & 1,00 & 0,41 & 0,56 & 0,00 & 1,47 & 1,09 & 0,93 \\
\hline Leste & 0,00 & 1,00 & 1,24 & 1,75 & 0,44 & 1,24 & 2,05 & 1,57 \\
\hline Oeste & 0,00 & 1,00 & 1,26 & 1,92 & 0,65 & 1,20 & 2,02 & 1,27 \\
\hline $\begin{array}{c}\text { ZB6 A } \\
\text { ZB8 }\end{array}$ & SP & VRTQR & L23 & $\mathrm{TN}$ & V90 & V45 & PTI & PTF \\
\hline Norte & 0,00 & 1,00 & 1,19 & 0,78 & 0,00 & 0,94 & 1,33 & 1,17 \\
\hline Sul & 0,00 & 1,00 & 0,32 & 0,56 & 0,00 & 1,38 & 0,98 & 0,85 \\
\hline Leste & 0,00 & 1,00 & 0,95 & 1,49 & 0,22 & 0,95 & 1,68 & 1,40 \\
\hline Oeste & 0,00 & 1,00 & 0,93 & 1,57 & 0,34 & 0,95 & 1,57 & 1,24 \\
\hline $\begin{array}{c}\text { TODA } \\
\text { S ZB }\end{array}$ & SP & VRTQR & L23 & TN & V90 & V45 & PTI & PTF \\
\hline Norte & 0,00 & 1,00 & 1,36 & 0,73 & 0,00 & 1,21 & 1,52 & 1,37 \\
\hline Sul & 0,00 & 1,00 & 0,20 & 0,41 & 0,00 & 1,50 & 0,81 & 0,70 \\
\hline Leste & 0,00 & 1,00 & 1,02 & 0,89 & 0,23 & 1,45 & 2,09 & 1,85 \\
\hline Oeste & 0,00 & 1,00 & 1,02 & 1,02 & 0,49 & 1,09 & 1,50 & 1,37 \\
\hline
\end{tabular}


Em geral, os resultados apresentados na Tabela 9 mostram existir diferenças significativas entre os valores de pontuação resultantes das simulações realizadas e os valores praticados pelo RTQ-R com pontuações significativamente superiores à máxima atribuída às venezianas. Outro aspecto importante a destacar é que as pontuações variam significativamente e que, por isso, se observou a necessidade de se adotarem valores de pontuação separada por zona bioclimática e por orientação solar.

Verifica-se pelos valores da Tabela 9 que a zona bioclimática 1 apresenta menor necessidade de sombreamento, inclusive com desempenho negativo dos sistemas de sombreamento em algumas orientações, como observado anteriormente. Já para as demais zonas bioclimáticas a utilização de proteção solar nas aberturas apresenta, de maneira geral, melhoria de desempenho térmico do ambiente (exceção feita à fachada sul para dispositivos do tipo PTF). Verifica-se, ainda, que alguns sistemas possibilitam diminuir o número de graus-hora em mais de duas vezes quando comparados às venezianas simuladas para nota 1 no RTQ-R. Esse fenômeno ocorre inclusive para venezianas com acionamento diferenciado daquele estabelecido pelo RTQ-R (V45 para norte na ZB4, por exemplo).

\section{Sugestões de alteração do RTQ-R}

As análises realizadas nesta pesquisa permitiram identificar algumas possibilidades para alteração do sistema de avaliação e do peso da variável Somb no RTQ-R quando se tratar de dispositivos de proteção solar hoje abordados pelos métodos do Anexo I e pelo método da latitude. Os resultados apresentados mostraram grande variabilidade do desempenho de um mesmo método de dimensionamento de dispositivos de proteção solar de acordo com a zona bioclimática inserida e a orientação solar.

Verificou-se que o método de dimensionamento de dispositivos de sombreamento com base na temperatura neutra (método TN), ao não indicar sombreamento para diversas fachadas com aberturas pequenas, apresentou subdimensionamento do sombreamento. Além disso, quando esse dimensionamento foi indicado, a pontuação dos elementos de sombreamento equivaleria a um valor superior a 0,5 , o que parece evidenciar a necessidade de revisão da pontuação atribuída às aberturas avaliadas pelo método TN.

A pesquisa apresentada mostrou também que os elementos de sombreamento definidos pelos ângulos gerados pelos métodos PTI e PTF (métodos para sombreamento das horas úteis de disponibilidade de luz natural) apresentaram dimensões próximas àquelas obtidas pelo método L23 (dimensionamento em função da latitude RTQ-R). Contudo, para as orientações leste e oeste, observou-se haver maior necessidade de sombreamento. Sendo assim, propõem-se aqui ângulos maiores correspondentes aos dos modelos PTI e PTF. A proposta para avaliação dos ângulos de proteção solar apresentada na Tabela 10 indica que para a pontuação a proteção horizontal deverá sempre ser existente e conjugada com os ângulos $\beta$ ou $\gamma$.

Em função da necessidade ou não de sombreamento detectada para cada zona bioclimática e orientação, a pontuação máxima para o Somb de cada abertura foi então proposta conforme indicado na Tabela 11.

\section{Tabela 10 - Proposta de ângulos para dimensionamento mínimo a ser considerado para pontuação dos dispositivos de proteção solar externos que não venezianas para cálculo da variável Somb por orientação solar}

\begin{tabular}{|c|c|c|c|c|}
\hline Orientação/ângulos & $\mathbf{A}$ & \multirow{5}{*}{$\begin{array}{l}\text { Conjugado } \\
\text { com: }\end{array}$} & $\beta$ ou $\gamma$ e & $\beta d$ ou $\gamma d$ \\
\hline Norte & $23,5^{\circ}-$ Lat & & $23,5^{\circ}$ - Lat ou $75^{\circ}$ & $23,5^{\circ}$ - Lat ou $75^{\circ}$ \\
\hline Sul & $23,5^{\circ}+$ Lat & & $23,5^{\circ}+$ Lat ou $75^{\circ}$ & $23,5^{\circ}+$ Lat ou $75^{\circ}$ \\
\hline Leste & $75^{\circ}$ & & $23,5^{\circ}-$ Lat & $23,5^{\circ}+$ Lat \\
\hline Oeste & $75^{\circ}$ & & $23,5^{0}+$ Lat & $23,5^{\circ}$ - Lat \\
\hline
\end{tabular}

Nota: Legenda:

Lat: valor da latitude do local (valores negativos para o hemisfério Sul);

$\alpha$ : ângulo de proteção horizontal;

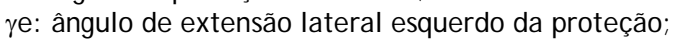

$\gamma$ d: ângulo de extensão lateral direito da proteção;

$\beta e$ : ângulo de proteção vertical esquerdo; e

$\beta \mathrm{d}$ : ângulo de proteção vertical direito. 
Tabela 11 - Proposta de pontuação máxima da variável Somb para elementos de proteção solar externos que não venezianas por zona bioclimática

\begin{tabular}{l|c|c|c}
\hline Orientação & ZB1 & ZB2 e ZB3 & ZB4 a ZB8 \\
\hline Norte & 0 & 1,0 & 1,0 \\
Sul & 0 & 0 & 0,4 \\
Leste & 0 & 1,0 & 1,0 \\
Oeste & 1,0 & 1,0 & 1,0 \\
\hline
\end{tabular}

No caso da existência de mais de uma abertura no ambiente, a pontuação por orientação solar deverá ser ponderada pela área de cada abertura conforme a Equação 3.

Somb $_{\text {abertura }}=\frac{A a_{N} \cdot \operatorname{Somb}_{N}+A a_{S} \cdot \operatorname{Somb}_{S}+A a_{L} \cdot \operatorname{somb}_{L}+A a_{O} \cdot \text { Somb }_{O}}{A a_{\text {total }}}$

Eq. 3

Sugere-se que o método proposto aqui possa substituir os dois métodos diferentes de dimensionamento apresentados no RTQ-R, de forma a simplificar as avaliações e a avaliar de maneira considerada mais adequada a presença de sombreamento nos projetos residenciais. Ressaltase que não se espera que os elementos de proteção solar sejam dimensionados seguindo-se as dimensões apontadas na Tabela 10, mas, sim, que os elementos eventualmente existentes para proteção solar das aberturas sejam mais corretamente pontuados em função das dimensões existentes em projeto.

\section{Conclusões}

Este trabalho buscou investigar através de simulações computacionais o desempenho de diferentes dispositivos de proteção solar em relação ao aspecto luminoso e térmico dos ambientes. A partir dos resultados obtidos nas simulações computacionais, verificou-se o valor que a variável Somb poderia obter para cada um dos dispositivos estabelecidos, comparando-se estes aos modelos sem proteção e aos modelos com a veneziana VRTQ-R (que possui pontuação máxima na variável Somb). Os resultados mostraram que os valores de pontuação do Somb praticados pelo RTQ-R para dispositivos que não venezianas se mostraram subdimensionados e que o desempenho das proteções solares é fortemente relacionado às características climáticas e de orientação solar. Portanto, o trabalho indicou que o sistema de pontuação do Somb para proteções solares que não venezianas deve considerar não só as fachadas em que as aberturas estão inseridas, mas também a zona bioclimática em que as edificações se encontram.

Acredita-se que o método proposto para substituição da avaliação das proteções solares no RTQ-R possa unir os dois métodos atualmente existentes e dar um peso mais adequado à variável Somb quando não houver veneziana nas aberturas.

O dimensionamento de proteções solares é ainda um tema de difícil abordagem para a grande maioria dos profissionais. Considera-se que a simplificação da avaliação dos elementos de proteção solar pelo método prescritivo do RTQ-R possuiria o mérito de facilitar seu uso e vinculá-lo mais diretamente ao aumento de desempenho térmico dos ambientes.

A versão de 2008 da NBR 15575 indicava a necessidade de haver escurecimento noturno com garantia de manutenção da ventilação nos quartos. Apesar de essa obrigatoriedade ter sido retirada do texto na norma revista de 2013 (ABNT, 2013b), considera-se importante que seja garantido esse tipo de controle para os quartos, facilmente obtido com a presença de venezianas móveis integradas à abertura. No entanto, ao subvalorizar o potencial de sombreamento de dispositivos de proteção solar e incentivar o uso de venezianas para a obtenção da pontuação máxima pela variável Somb, o regulamento perde a possibilidade de incentivar maior aumento de conforto térmico e visual com o uso de elementos de sombreamento em ambientes de estar, onde o escurecimento noturno não é fundamental.

Ressalta-se, finalmente, que a avaliação do dimensionamento de proteções solares apresentada no presente trabalho não visa induzir a adoção de elementos de grandes dimensões, onerando os custos de obra, mas avaliar de forma considerada mais adequada as dimensões de elementos já adotados em projeto tais como varandas, toldos, beirais, pérgulas e brises.

\section{Referências}

\author{
ASSOCIAÇÃO BRASILEIRA DE NORMAS \\ TÉCNICAS. NBR 15575-1: edificações \\ habitacionais: desempenho: parte 1: requisitos \\ gerais. Rio de Janeiro, 2013a.
}

ASSOCIAÇÃO BRASILEIRA DE NORMAS TÉCNICAS. NBR 5413: iluminância de interiores. Rio de Janeiro, 1992. 
ASSOCIAÇÃO BRASILEIRA DE NORMAS TÉCNICAS. NBR ISO/CIE 8995-1: iluminação de ambientes de trabalho: parte 1: interior. Rio de Janeiro, 2013b.

BOGO, A. J.; PEREIRA, F. O. R.; CLARO, A. Controle Solar e Admissão de Luz Natural em Aberturas Com Proteção Solar. In: ENCONTRO NACIONAL DE CONFORTO NO AMBIENTE CONSTRUÍDO, 10., Natal, 2009. Anais... Natal, 2009.

BOURGEOIS, D.; REINHART, C.;

MACDONALD, I. Adding Advanced Behavioral Model in Whole Building Energy Simulation: a study on the total energy impact of manual and automated lighting control. Energy and Buildings, v. 38, n. 7, p. 814-823, 2006.

CARLETTI, C. et al. Thermal and Lighting Effects of an External Venetian Blind: experimental analysis in a full scale test room. Building and Environment, v. 106, p. 45-56, 2016.

CINTRA, M. S. Arquitetura e Luz Natural: a influência da profundidade de ambientes em edificações residenciais. Brasília, 2011. Dissertação (Mestrado em Arquitetura e Urbanismo) - Escola de Arquitetura, Universidade de Brasília, Brasília, 2011.

DE LIMA, K. M.; BITTENCOURT, L. S.; CARAM, R. M. Ranking Configurations of Shading Devices by Its Thermal and Luminous Performance. In: PLEA, 3., Munich, 2013.

Proceedings... Munich, 2013.

DIDONÉ, E. L. A influência da Luz Natural na Avaliação da Eficiência Energética de Edifícios Contemporâneos de Escritórios em Florianópolis. Florianópolis, 2009. Dissertação (Mestrado em Arquitetura e Urbanismo) Programa de Pós-Graduação em Arquitetura e Urbanismo, Universidade Federal de Santa Catarina, Florianópolis, 2009.

FONTENELLE, M. R.; BASTOS, L. E. G. The Multicriteria Approach in the Architecture Conception: defining windows for an office building in Rio de Janeiro. Building and Environment, v. 74, p. 96-105, apr. 2014.

GUEDES, A. F. Análise da Iluminação Natural a Partir do "Regulamento Técnico da Qualidade para Eficiência Energética de Edifícios Residenciais": simulação em edifícios multifamiliares de Belo Horizonte. Belo Horizonte, 2012. Dissertação (Mestrado em Ambiente Construído e Patrimônio Sustentável) Escola de Arquitetura e Design, Universidade Federal de Minas Gerais, Belo Horizonte, 2012.
INSTITUTO NACIONAL DE METROLOGIA, NORMALIZAÇÃO E QUALIDADE

INDUSTRIAL. Portaria no 18, de 16 de janeiro de 2012, que regulamento Técnico da Qualidade para o Nível de Eficiência Energética de Edificações Residenciais. Rio de Janeiro, 2012.

IWARO, J.; MWASHA, A. A Review of Building Energy Regulation and Policy For Energy Conservation in Developing Countries. Energy Policy, v. 38, n. 12, p. 7744-7755, 2010.

LABORATÓRIO DE EFICIÊNCIA ENERGÉTICA EM EDIFICAÇÕES. Relatório

Técnico RT_LABEEE-2011/02: desenvolvimento da base de simulações para o RTQ-R.

Florianópolis, 2011.

\section{LABORATÓRIO DE EFICIÊNCIA} ENERGÉTICA EM EDIFICAÇÕES. Relatório Técnico RT_LABEEE-2011b: desenvolvimento da base de simulações para o RTQ-R. Florianópolis, 2011b. Disponível em : <http://www.labeee.ufsc.br/projetos/etiquetagem/d esenvolvimento/atividades-2008-2011/trabalhoii>. Acesso em: 5 jan. 2013.

LEE, D.-S. et al. Evaluating Thermal and Lighting Energy Performance of Shading Devices on Kinetic Façades. Sustainability, v. 8, n. 9, p. 883, 2016.

LIMA, K. M. de; BITTENCOURT, L. S.; CARAM, R. M. Ranking Configurations of Shading Devices by Its Thermal and Luminous Performance. In: PLEA 2013: SUSTAINABLE ARCHITECTURE FOR A RENEWABLE FUTURE, 29., Munich, 2013. Anais... Munich: Fraunhofer IRB Verlag, 2013.

MANZAN, M. Genetic Optimization of External Fixed Shading Devices. Energy and Buildings, v. 72, p. 431-440, 2014.

PBE Edifica. Nota Técnica 06/2012. nota técnica referente à correção da equação de cálculo do valor da variável "somb” pelo método da latitude. 2012. Disponível em:

$<$ http://www.pbeedifica.com.br/sites/default/files/ NT06_NR_Somb\%20latitude.pdf $>$. Acesso em: 5 dez. 2017.

PEREIRA, I. M.; SOUZA, R. V. G. Proteção Solar em Edificações Residenciais e Comerciais: desenvolvimento de metodologia. In: ENCONTRO NACIONAL DE TECNOLOGIA DO AMBIENTE CONSTRUÍDO, 12., Fortaleza, 2008. Anais... Fortaleza: ANTAC, 2008.

REINHART, C. F. Tutorial on the Use of Daysim Simulations For Sustainable Design. Institute for Research in Construction, National Research Council Canada, Canadá, 2010. 
REINHART, C. F.; VOSS, K. Monitoring Manual Control of Electric Lighting and Blinds. Lighting Research \& Technology, v. 35, n. 2, 2003.

SANTANA, M. V.; GHISI, E. Influência de Parâmetros Construtivos Relacionados ao Envelope no Consumo de Energia de Edifícios de Escritório da cidade De Florianópolis. In: ENCONTRO NACIONAL, 10.; ENCONTRO LATINO-AMERICANO DE CONFORTO NO AMBIENTE CONSTRUÍDO, 6., Natal, 2009. Anais... Natal, 2009.

SANTOS, I. G. Análise de Envoltória e do Sistema de Iluminação a Partir do "Regulamento Técnico da Qualidade Para Eficiência Energética de Edifícios Comerciais, de Serviços e Públicos” Para Avaliação de Desempenho de Sistemas de Fachada e de Proteções Solares. Belo Horizonte, 2009. Dissertação (Mestrado em Ambiente Construído e Patrimônio Sustentável) - Universidade Federal de Minas Gerais, Belo Horizonte, 2009.
SILVA, V. S. C. A Influência dos Protetores Solares no Comportamento da Luz Natural em Edifícios de Escritórios. Brasília, 2011.

Dissertação (Mestrado em Arquitetura e Urbanismo) - Programa de Pesquisa e PósGraduação, Faculdade de Arquitetura e Urbanismo, Universidade de Brasília, Brasília, 2011.

\section{SOUZA, M. B. Potencialidade de}

Aproveitamento da Luz Natural Através da Utilização de Sistemas Automáticos de Controle Para Economia de Energia Elétrica.

Florianópolis, 2003. Tese (Doutorado em Engenharia de Produção) - Centro Tecnológico, Universidade Federal de Santa Catarina, Florianópolis, 2003.

TELLES, C. P.; CARLO, J. Sensibilidade dos Parâmetros Termo Físicos do RTQ-R: análise de acordo com o método prescritivo. Cadernos do PROARQ, v. 26, p. 100-114, 2016.

Roberta Vieira Gonçalves de Souza

Departamento de Tecnologia da Arquitetura e do Urbanismo, Escola de Arquitetura | Universidade Federal de Minas Gerais | Rua Paraíba, 697, Sala 124, Funcionários | Belo Horizonte - MG - Brasil | CEP 30130-140 | Tel.: (31) 3409-8872 | E-mail: roberta@arq.ufmg.br

\section{Carla Patrícia Santod Soares}

Ares Arquitetura Ltda ME | Rua Rio Grande do Norte, 1560, Sala 604, Funcionários | Belo Horizonte - MG - Brasil | CEP $30130-131$ | Tel.: (31) 2516-8777| E-mail: pati.incd@gmail.com

\section{Tatiana Paula Alves}

Centro Universitário UNA | Rua Aimorés, 1451, Lourdes Belo Horizonte - MG - Brasil | CEP 30140-071| Tel.: (31) 2516-8777| E-mail: alvestatianapaula@gmail.com

\section{Revista Ambiente Construído}

Associação Nacional de Tecnologia do Ambiente Construído

Av. Osvaldo Aranha, 99 - 3o andar, Centro

Porto Alegre - RS - Brasil CEP $90035-190$

Telefone: +55 (51) 3308-4084

Fax: +55 (51) 3308-4054

www. seer. ufrgs. br/ ambienteconstruido

E-mail: ambienteconstruido@ufrgs.br 